\title{
Cerebral Blood Flow, Heart Rate, and Blood Pressure Patterns during the Tilt Test in Common Orthostatic Syndromes
}

\author{
Peter Novak \\ Department of Neurology, Brigham and Women's Faulkner Hospital, Harvard Medical School, Boston, MA 02130, USA \\ Correspondence should be addressed to Peter Novak; pnovak2@partners.org
}

Received 22 February 2016; Revised 28 April 2016; Accepted 25 May 2016

Academic Editor: Rainer Surges

Copyright (C) 2016 Peter Novak. This is an open access article distributed under the Creative Commons Attribution License, which permits unrestricted use, distribution, and reproduction in any medium, provided the original work is properly cited.

Objective. The head-up tilt test is widely used for evaluation of orthostatic intolerance. Although orthostatic symptoms usually reflect cerebral hypoperfusion, the cerebral blood flow velocity $(\mathrm{CBFv})$ profile in orthostatic syndromes is not well described. This study evaluated CBFv and cardiovascular patterns associated with the tilt test in common orthostatic syndromes. Methods. This retrospective study analyzed the tilt test of patients with history of orthostatic intolerance. The following signals were recorded: ECG, blood pressure, $\mathrm{CBFv}$ using transcranial Doppler, respiratory signals, and end tidal $\mathrm{CO}_{2}$. Results. Data from 744 patients were analyzed. Characteristic pattern associated with a particular orthostatic syndrome can be grouped into abnormalities predominantly affecting blood pressure (orthostatic hypotension, orthostatic hypertension syndrome, vasomotor oscillations, and neurally mediated syncope-cardioinhibitory, vasodepressor, and mixed), cerebral blood flow (orthostatic hypoperfusion syndrome, primary cerebral autoregulatory failure), and heart rate (tachycardia syndromes: postural tachycardia syndrome, paroxysmal sinus tachycardia, and inappropriate sinus tachycardia). Psychogenic pseudosyncope is associated with stable CBFv. Conclusions. The tilt test is useful add-on in diagnosis of several orthostatic syndromes. However diagnostic criteria for several syndromes had to be modified to allow unambiguous pattern classification. CBFv monitoring in addition to blood pressure and heart rate may increase diagnostic yield of the tilt test.

\section{Introduction}

The head-up tilt testing is widely used in diagnosis of orthostatic intolerance. The tilting provokes blood pooling in the splanchnic and the lower extremity circulation which triggers the neural and humoral compensatory mechanisms aiming to maintain stable blood pressure and cerebral perfusion. The tilt test assesses the integrity of parasympathetic and sympathetic innervation [1]. The tilt test was initially introduced to diagnose vasovagal syncope [2]. Since then the diagnostic utility of the tilt test has been expanded for diagnosis of orthostatic hypotension, autonomic failure, postural tachycardia syndrome, and other forms of orthostatic intolerance [3].

Common orthostatic symptoms are usually defined by heart rate and blood pressure responses to tilting. The orthostatic cerebral blood flow is less studied; even many orthostatic symptoms are due to orthostatic cerebral hypoperfusion [4]. Therefore, the purpose of this study was to analyze the cerebral blood flow and cardiovascular patterns in common orthostatic syndromes.

\section{Methods}

Standard Protocol Approvals, Registrations, and Patient Consents. The study was approved by the Institutional Review Board of the University of Massachusetts Medical School as a minimal risk study.

2.1. Participants. This retrospective, single-center study included patients with history of autonomic function testing at the University of Massachusetts Medical School, Autonomic Laboratory, between years 2007 and 2014. Patients were referred for evaluation of two types of orthostatic complaints. The first group constitutes orthostatic intolerance symptoms which include dizziness, lightheadedness, unexplained falls, chronic fatigue, heaviness, chest pain, and shortness of 
breath. The second group includes patients with history of unexplained loss of consciousness that were referred for evaluation of suspected syncope.

2.2. Autonomic Cardiovascular Testing. The details of our standardized testing protocol have been published previously [5]. Autonomic testing included deep breathing, Valsalva maneuver, and the tilt test. Only the tilt test results are reported here. After a resting supine period of at least 10 minutes duration, subjects were tilted at 70 degrees for 10 minutes or longer if patients can tolerate. During the whole testing, heart rate, blood pressure, respiratory movement, and cerebral blood flow velocity (CBFv) were monitored.

Heart rate was calculated from ECG. Arterial blood pressure was measured in the upper arm intermittently using an automated noninvasive oscillometric device Dinamap ProCare Monitor 100 (GE, Fairfield, CT), as well as continuously by infrared finger plethysmography (Finapress Medical Systems, Amsterdam, Netherlands). Nasal thermistor and end tidal $\mathrm{CO}_{2}$ (Capstar-100, CWE, Inc., Ardmore, PA) were used for monitoring respiratory parameters. $\mathrm{CBFv}$ was monitored using transcranial Doppler (MultiDop T, DWL, Singen, Germany) with a $2 \mathrm{MHz}$ probe. $\mathrm{CBFv}$ was obtained from the left middle cerebral artery with the Doppler probe attached to a three-dimensional positioner which kept the probe at a constant depth and angle of insonation.

The tilt responses were classified as described below.

2.2.1. Normal Response. Normally heart rate increases at least 10 beats per minute (BPM) but less than $30 \mathrm{BMP}$ during the tilt (Table 1) $[3,6]$. Normal blood pressure responses are also restricted within a range. The normal response is a drop of systolic blood pressure $<20 \mathrm{mmHg}$ and diastolic blood pressure $<10 \mathrm{mmHg}$ on upright posture. The systolic blood pressure may normally rise up to $20 \mathrm{mmHg}$. Normal response of $\mathrm{CBFv}$ to the tilting is a mild drop. Since the baseline CBFv is gender and age dependent, the orthostatic criteria are given in relative values where the supine baseline is $100 \%$. The threshold for normal drop of the mean CBFv is $90 \%$ (1st minute), 89\% (5th minute), and 85\% (10th minute) of the supine baseline $(=100 \%)$ which immediately precedes the tilt [6].

2.2.2. Postural Tachycardia Syndrome (POTS). POTS is defined by the presence of orthostatic symptoms associated with an increment of heart rate by $\geq 30$ BPM held for more than 30 seconds when changing position from supine to upright in the absence of orthostatic hypotension [7]. The timing of heart rate increment is either not mentioned [7] or defined within 5 minutes [8] or within 10 minutes or longer [9] of the upright posture. Early description of POTS also required the absolute heart rate $120 \mathrm{BPM}$ or more, while the heart rate below 120 during the tilt test was termed as mild orthostatic intolerance [8]. The supine heart rate is not mentioned in any POTS definitions. To avoid overlap with the definition of the inappropriate sinus tachycardia (see below), an additional criterion for the POTS is average heart rate $<100 \mathrm{BPM}$ during supine baseline before the tilting.
The CBFv may be abnormally decreased during tilting due to hyperventilation induced hypocapnia during the tilt [4]. Table 1 shows exact POTS criteria.

2.2.3. Orthostatic Hypotension $(\mathrm{OH})$. Historically, $\mathrm{OH}$ is defined as a drop $\geq 20 \mathrm{mmHg}$ in systolic blood pressure or $\geq 10 \mathrm{mmHg}$ in diastolic blood pressure within three minutes of standing or head-up tilt. This definition does not take into account the baseline value; therefore a modified definition was that using a relative drop of $80 \%$ and $85 \%$ in systolic and mean blood pressure, respectively, where supine baseline is $100 \%[6]$.

2.2.4. Orthostatic Hypertension Syndrome (OHTN). OHTN is a common syndrome with a prevalence of $1.1 \%$ [10] and occurs in $16.3 \%$ of older hypertensive patients [11]. OHTN is defined as a postural increase of systolic blood pressure by at least $20 \mathrm{mmHg}$ [12] or an increase in systolic blood pressure during the tilt to $120 \%$ and above where supine baseline is equal to $100 \%$ [6]. The latter definition was used in this study since it accounts for a supine baseline. Little is known about CBFv in OHTN.

2.2.5. Neurally Mediated (Reflex) Syncope. Syncope is defined as a transient loss of consciousness due to global cerebral hypoperfusion [13]. Neurally mediated, also called reflex, neurocardiogenic, or vasovagal, syncope is a syncope triggered by a neural reflex resulting in systemic hypotension, reduced cardiac output, peripheral vasodilatation, and/or bradycardia [14]. Characteristic sign of neurocardiogenic syncope is profound hypotension during the tilt test. Based on the heart rate responses, syncope can be divided into three forms: cardioinhibitory, vasodepressor, and mixed which is the most common. In general, the vasodepressor syncope is due to a predominant loss of upright vasoconstrictor tone. Bradycardia or asystole predominates in cardioinhibitory syncope and both mechanisms (vasodilatation and cardioinhibition) are present in mixed syncope [3]. CBFv has characteristic pattern during syncope consistent with cerebral vasodilation as indicted by increased systolic and decreased diastolic CBFv and thus increased pulsatility index defined as systolic CBFv - diastolic CBFv [15]. In this study, the VASIS (Vasovagal Syncope International Study) classification [16] of syncope has been expanded using the CBFv and blood pressure criteria (Table 1).

2.2.6. Pseudosyncope: Psychogenic Syncope. In psychogenic syncope, also termed psychogenic pseudosyncope, consciousness is only apparently lost and global cerebral hypoperfusion is absent [3]. In this study, the psychogenic syncope was defined as an apparent loss of consciousness without changes in $\mathrm{CBFv}$ indicative of syncope.

2.2.7. Paroxysmal Sinus Tachycardia (PST). PST can be frequently encountered during the tilt test and may be due to underlying anxiety disorder. Paroxysmal PST in this study was defined as intermittent (duration $<2$ minutes) tachycardia (heart rate $>100 \mathrm{bpm} \mathrm{[17])} \mathrm{associated} \mathrm{with} \mathrm{heart}$ 
TABLE 1: Criteria for the orthostatic syndromes.

\begin{tabular}{|c|c|c|}
\hline Disorder/syndrome & Criteria & Comments \\
\hline Normal response to tilt & $\begin{array}{l}\text { QASAT [1] - bradycardia supine }=0 \text { AND } \\
\text { QASAT [3] - increased heart rate response to tilt }=0 \\
\text { QASAT [7]-orthostatic hypotension during the tilt }=0 \text { AND } \\
\text { QASAT [10]—orthostatic hypertension during the tilt }=0 \text { AND } \\
\text { QASAT [15] - cerebral blood flow response to tilt }=0\end{array}$ & \\
\hline $\begin{array}{l}\text { Orthostatic hypotension } \\
(\mathrm{OH}) \text {, compensated, } \\
\text { with stable orthostatic } \\
\text { CBFv }\end{array}$ & $\begin{array}{l}\text { QASAT [7] -orthostatic hypotension during the tilt }>0 \text { AND } \\
\text { QASAT [15] - cerebral blood flow response to tilt }=0\end{array}$ & \\
\hline $\begin{array}{l}\mathrm{OH} \text {, uncompensated, } \\
\text { with reduced orthostatic } \\
\mathrm{CBFv}\end{array}$ & $\begin{array}{l}\text { QASAT [7] -orthostatic hypotension during the tilt }>0 \text { AND } \\
\text { QASAT [15] - cerebral blood flow response to tilt }>0\end{array}$ & \\
\hline $\begin{array}{l}\text { Orthostatic cerebral } \\
\text { hypoperfusion } \\
\text { syndrome (OCHOs) }\end{array}$ & $\begin{array}{l}\text { QASAT [7] —orthostatic hypotension during the tilt }=0 \text { AND } \\
\text { QASAT [15] - cerebral blood flow response to tilt }>1 \text { AND } \\
\text { QASAT [3] - increased heart rate response to tilt }=0\end{array}$ & \\
\hline $\begin{array}{l}\text { Orthostatic } \\
\text { hypertension syndrome } \\
\text { (OHTN) }\end{array}$ & $\begin{array}{l}\text { QASAT [7] - orthostatic hypotension during the tilt }=0 \text { AND } \\
\text { QASAT [10]—orthostatic hypertension during the tilt }=1 \text { AND } \\
\text { QASAT [15] - cerebral blood flow response to tilt }=0 \text { AND } \\
\text { QASAT [3] - increased heart rate response to tilt }=0\end{array}$ & \\
\hline $\begin{array}{l}\text { Postural tachycardia } \\
\text { syndrome (POTS) }\end{array}$ & $\begin{array}{l}\text { QASAT [7] - orthostatic hypotension during the tilt }=0 \text { AND } \\
\text { average supine heart rate before the tilt }<100 \text { BMP AND } \\
\text { maximal heart rate increment during the tilt } \geq 30 \text { BMP AND } \\
\text { the duration of the increment } \geq 3 \text { minutes AND } \\
\text { the maximal absolute heart rate during the increment } \geq 120 \text { BPM }\end{array}$ & $\begin{array}{l}\text { If the maximal heart rate does not cross } \\
120 \mathrm{BMP} \text {, it is called mild orthostatic } \\
\text { intolerance }\end{array}$ \\
\hline $\begin{array}{l}\text { Inappropriate sinus } \\
\text { tachycardia (IST) }\end{array}$ & $\begin{array}{l}\text { QASAT [7] - orthostatic hypotension during the tilt }=0 \text { AND } \\
\text { average supine heart rate before the tilt } \geq 100 \text { BMP AND } \\
\text { heart rate increment during the tilt } \geq 30 \text { BMP }\end{array}$ & Grading is based on maximal heart rate \\
\hline $\begin{array}{l}\text { Paroxysmal sinus } \\
\text { tachycardia (PST) }\end{array}$ & $\begin{array}{l}\text { QASAT [7] - orthostatic hypotension during the tilt }=0 \text { AND } \\
\text { average supine heart rate before the tilt }<100 \text { BMP AND } \\
\text { maximal heart rate increment during the tilt } \geq 30 \text { BMP AND } \\
\text { the duration of the increment }<3 \text { minutes AND } \\
\text { the maximal absolute heart rate during the increment } \geq 120 \text { BPM }\end{array}$ & $\begin{array}{l}\text { PST usually affects the first } 2 \text { minutes of the } \\
\text { tilt but not always. If, for example, the } \\
\text { tachycardia with the } 30 \mathrm{BPM} \text { increment } \\
\text { occurs at minutes } 9 \text { and } 10 \text { of the tilt (the } \\
\text { tachycardia duration = } 2 \text { minutes), then it is } \\
\text { recommended to continue the tilt to clarify } \\
\text { the diagnosis. If the tachycardia continues it } \\
\text { is the POTS; if not it is PST }\end{array}$ \\
\hline Syncope, cardiovagal & $\begin{array}{l}\mathrm{HR}<40 \mathrm{BPM} \text { AND } \\
\text { systolic } \mathrm{BP}<60 \mathrm{mmHg} \text { AND } \\
\text { diastolic } \mathrm{CBFv}<5 \mathrm{~cm} / \mathrm{sec}\end{array}$ & $\begin{array}{l}\text { All variables are obtained during the } \\
\text { syncope }\end{array}$ \\
\hline Syncope, vasodepressor & $\begin{array}{l}\mathrm{HR} \geq \text { before syncope AND } \\
\text { systolic } \mathrm{BP}<60 \mathrm{mmHg} \text { AND } \\
\text { diastolic } \mathrm{CBFv}<5 \mathrm{~cm} / \mathrm{sec}\end{array}$ & $\begin{array}{l}\text { All variables are obtained during the } \\
\text { syncope }\end{array}$ \\
\hline Syncope, mixed & $\begin{array}{l}\mathrm{HR}>40 \mathrm{BPM} \text { AND } \\
\mathrm{HR}<\text { before syncope AND } \\
\text { systolic } \mathrm{BP}<60 \mathrm{mmHg} \text { AND } \\
\text { diastolic } \mathrm{CBFv}<5 \mathrm{~cm} / \mathrm{sec}\end{array}$ & $\begin{array}{l}\text { All variables are obtained during the } \\
\text { syncope }\end{array}$ \\
\hline $\begin{array}{l}\text { Primary cerebral } \\
\text { autoregulatory failure }\end{array}$ & $\begin{array}{l}\text { QASAT [13] - supine cerebral low flow }=1 \text { AND } \\
\text { QASAT [6] - supine hypotension }=0\end{array}$ & \\
\hline $\begin{array}{l}\text { Psychogenic } \\
\text { pseudosyncope }\end{array}$ & $\begin{array}{l}\text { QASAT [15] - cerebral blood flow response to tilt = } 0 \text { AND } \\
\text { physical examination indicative of apparent loss of consciousness }\end{array}$ & $\begin{array}{l}\text { Typically patient is unresponsive, atonic, } \\
\text { although bizarre posturing can be observed, } \\
\text { without abnormal movement that can be } \\
\text { seen in seizures }\end{array}$ \\
\hline
\end{tabular}

Comments: QASAT = Quantitative Scale for Grading of Cardiovascular Autonomic Reflex Tests and Small Fibers from Skin Biopsies, details of calculations can be found in Novak, 2015 [6]. $\mathrm{HR}=$ heart rate; $\mathrm{BP}=$ blood pressure; $\mathrm{CBFv}=$ cerebral blood flow velocity. 
rate increment $\geq 30$ BPM. The tachycardia can happen in both supine and upright positions.

2.2.8. Inappropriate Sinus Tachycardia (IST). IST is associated with persistent or recurrent elevated heart rate (>100 BMP) at rest including supine and excessive or inappropriate heart rate increment in upright position $[7,18]$. In this study the "inappropriate" heart rate increment was defined as $\geq 30$ BPM during the tilt [6].

2.2.9. Orthostatic Cerebral Hypoperfusion Syndrome (OCHOs). $\mathrm{OCHOs}$ is a recently described syndrome associated with reduced orthostatic cerebral blood flow velocity $(\mathrm{CBFv})$ without $\mathrm{OH}$, bradycardia, and excessive tachycardia [19]. OCHOs may be relatively common cause of orthostatic dizziness. Excessive tachycardia as defined in POTS is an exclusion criterion for OCHOs. OCHOs may result from cerebral vasoconstriction or abnormal venous pooling during upright position.

2.2.10. Primary Cerebral Autoregulatory Failure ( $p C A F$ ). This is a new syndrome defined in this paper. PCAF is characterized by abnormally low supine $\mathrm{CBFv}$ without supine hypotension. The normal supine $\mathrm{CBFv}$ is age and gender dependent and $\mathrm{pCAF}$ is defined as $\mathrm{CBFv}$ less than the lower limit of the normal range where the normal limit is $72.09-0.38 *$ age $\mathrm{cm} / \mathrm{s}$ and $82.2-0.45 *$ age $\mathrm{cm} / \mathrm{s}$ for men and women, respectively, using the MultiDop T device (Table 1) [6]. Since this pattern (e.g., low CBFv and normal or high BP) may indicate cerebral vasoconstriction, cerebral vascular resistance defined by mean blood pressure/mean CBFv [4] has been calculated as well.

2.2.11. Vasomotor Oscillations. Vasomotor oscillations are periodic fluctuations of blood pressure.

2.2.12. Spurious $\mathrm{OH}$ due to Inaccurate Plethysmographic Blood Pressure Measurement. Blood pressure acquired by finger plethysmographic device is not always accurate [20]. It is a policy at our autonomic laboratory to acquire blood pressure by both methods, for example, oscillometric and plethysmographic, and if the sustained difference is more than $10 \%$, then finger device should be repositioned. In the case the difference persists, blood pressure from plethysmographic device should be recalibrated using the oscillometric device.

The syndromes described above were detected automatically by an algorithm written in Matlab programming language (MathWorks, Natick, MA). The software used in this study is an extension of the Quantitative Scale for Grading of Cardiovascular Autonomic Reflex Tests and Small Fibers from Skin Biopsies (QASAT) [6], also written in Matlab. QASAT is an objective and validated instrument for grading of tilt responses which defines normal and abnormal responses in heart rate, blood pressure, and $\mathrm{CBFv}$ during the tilt test. Table 1 provides exact criteria for each syndrome.

2.3. Statistical Analysis. The clinical variables associated with orthostatic syndromes were compared with normal responses using Wilcoxon rank test since most of the data had nonnormal distribution. Nine clinical syndromes were compared with the normal response to the tilt, for example, $\mathrm{OH}, \mathrm{OCHOs,}$ OHTN, POTS, IST, PST, syncope, psychogenic syncope, and $\mathrm{pCAF}$, and therefore the initial significance 0.05 was adjusted by Bonferroni correction to $0.005(0.05 / 10$ comparisons). All statistical analyses were performed using JMP 12.0 (Cary, NC) statistical software.

\section{Results}

Data from 744 patients were analyzed. All patients had unrevealing standardized evaluation including medical history, neurological examination, basic metabolic panel, 12-lead ECG, imaging studies (CT or MRI of the brain), and EEG if patients were referred for evaluation of syncope.

669 patients were referred for evaluation of orthostatic symptoms including dizziness and 75 patients were referred for evaluation of unexplained loss of consciousness with a suspected diagnosis of syncope.

The tilt test was normal in 102 subjects (Table 2). However, from these subjects, only 7 subjects had normal entire autonomic testing (e.g., QASAT total score $=0$ ). Remaining subjects had at least one abnormality in parasympathetic (evaluated by deep breathing test) or sudomotor (evaluated by QSART) functions.

From 669 patients evaluated for orthostatic intolerance (not syncope), the tilt test was normal in 77 patients. From 75 patients referred for evaluation of syncope, the tilt test showed normal response in 25 subjects, neutrally mediated syncope in 33 patients, and abnormal results but nonsyncope pattern in remaining patients (Table 2). Additional 23 patients that had syncope during the tilt test were referred for nonsyncope evaluation.

Table 2 shows details of orthostatic symptoms in each syndrome including the frequency of reproduction of previous symptoms that prompted autonomic testing and the frequency of a new diagnosis obtained from the tilt test. The symptoms were commonly reproduced in the PST (100\%), POTS (99\%), OCHOs (98\%), IST (86\%), and uncompensated $\mathrm{OH}(85 \%)$. Most common new diagnosis was obtained from the tilt test, which means the diagnosis was not mentioned in the chart or was not mentioned in the reason for the referral of the testing, which was OCHOs $(n=97), \operatorname{pCAF}(n=67)$, and POTS $(n=67)$.

Figures $1-3$ show common patterns encountered during the tilt testing. Figures 4-21 show and describe relevant details of each pattern. Figure 1 shows head-to-head comparisons of normal response, $\mathrm{OH}$ and OCHOs. Figure 2 compares the profile of common tachycardia syndromes including POTS, IST, and PST. Figure 3 shows three main types of syncope, for example, cardiovagal, vasodepressor, and mixed.

Syncope was associated with low blood pressure and CBFV (Table 2). Pure syncope pattern with otherwise normal responses on the tilt test was detected in 32 patients. Syncope was combined with other syndromes including POTS (12 patients), OHTN (1 patient), IST ( 3 patients), PST ( 3 patient), 


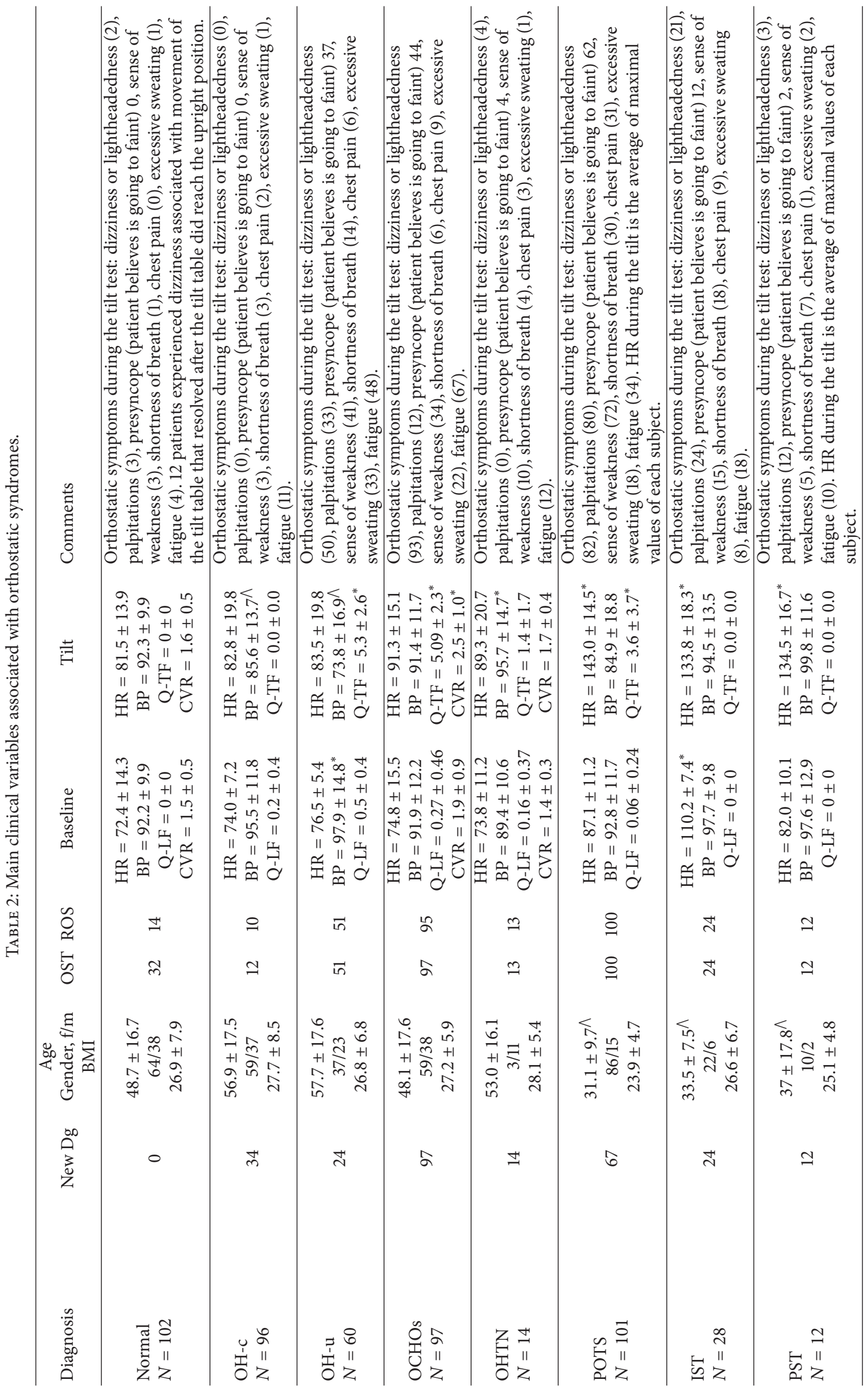




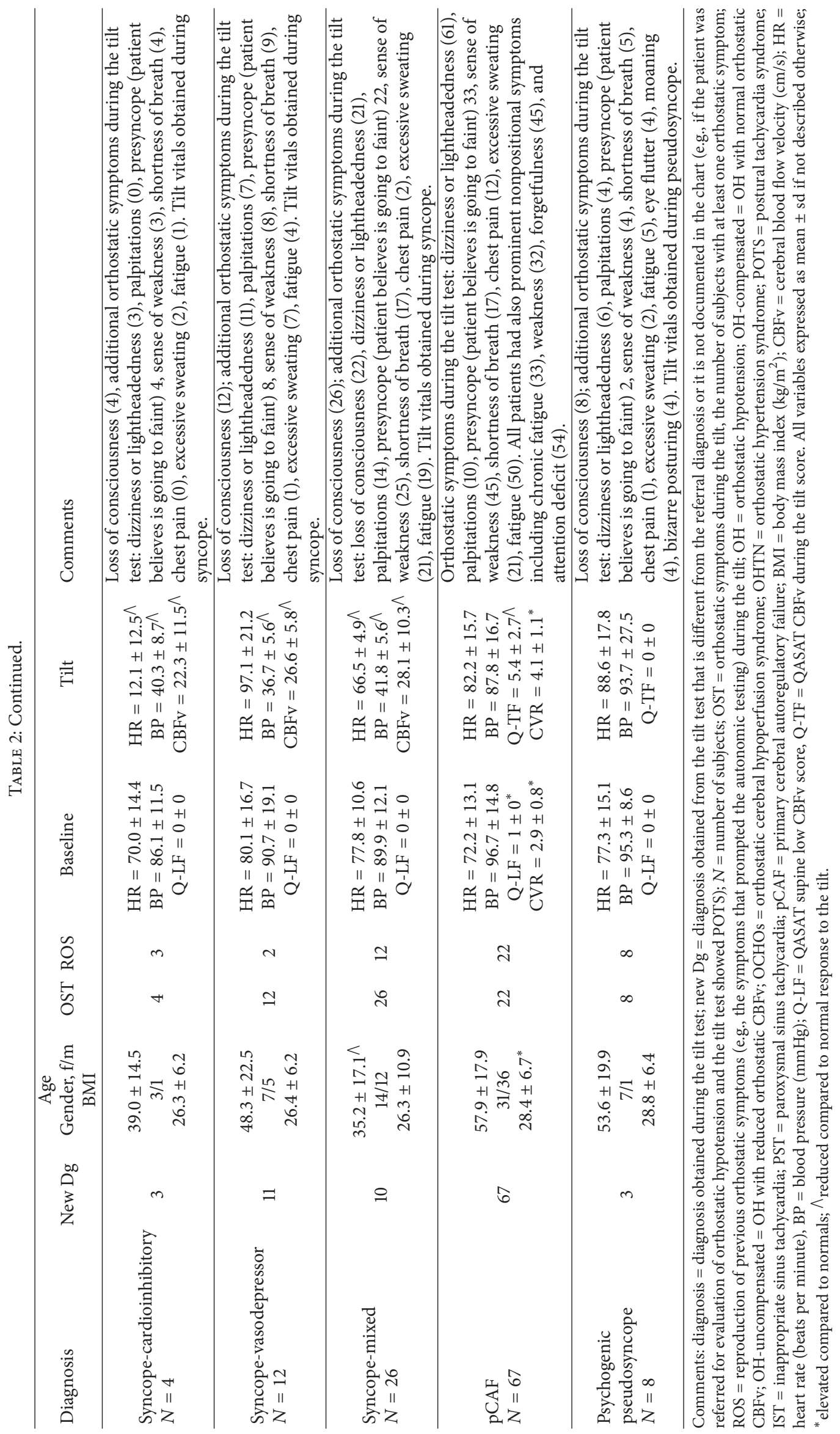



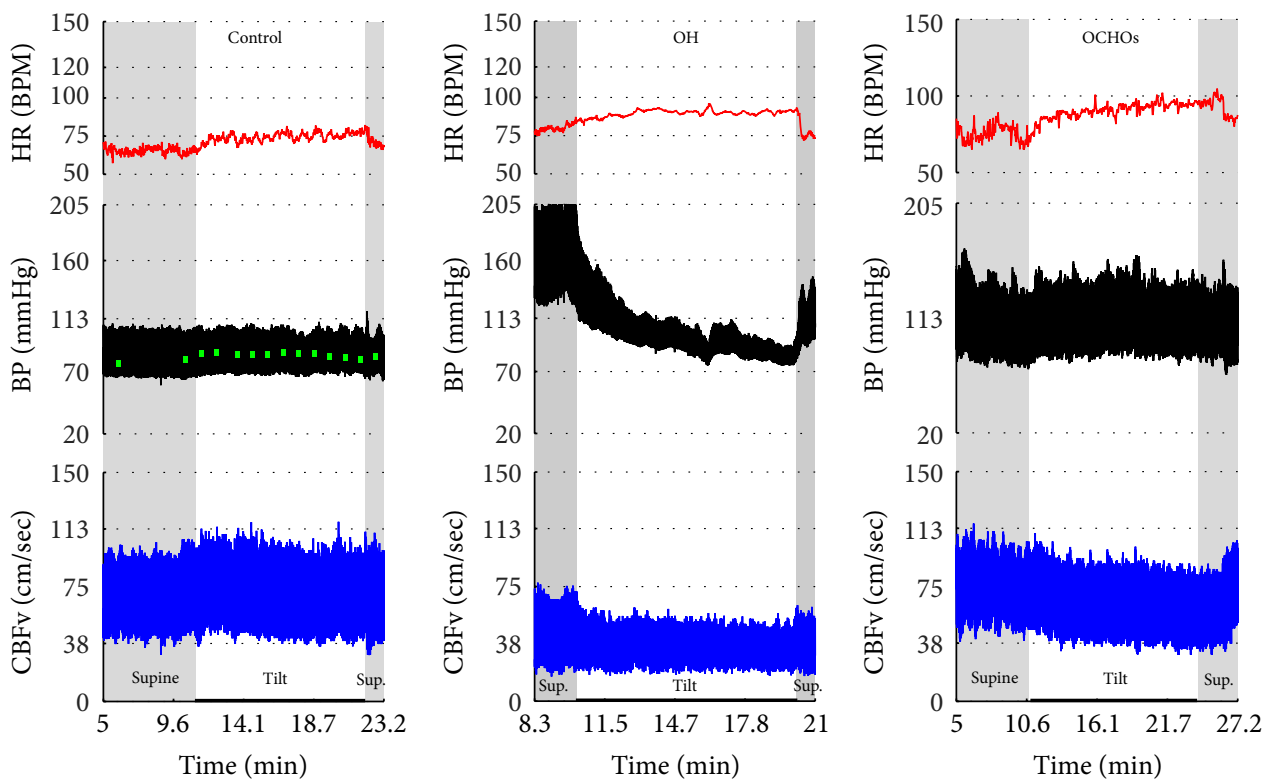

FIGURE 1: Comparisons of normal responses to the tilt (control), orthostatic hypotension $(\mathrm{OH})$, and orthostatic cerebral hypoperfusion syndrome (OCHOs). Normal heart rate increment ( $\geq 10$ and $<30 \mathrm{BPM}$ ) is seen in all examples. Orthostatic blood pressure is stable in a healthy control subject and $\mathrm{OCHO}$ while it is reduced in $\mathrm{OH}$. Orthostatic cerebral blood flow velocity is stable in a control subject and reduced in $\mathrm{OH}$ and OCHOs. $\mathrm{CBFv}$ can be normal or reduced in $\mathrm{OH}$, depending on functioning of cerebral autoregulation and severity of $\mathrm{OH}$. Green boxes represent mean blood pressure obtained from the upper arm. $\mathrm{HR}=$ heart rate, $\mathrm{BP}=$ blood pressure, and $\mathrm{CBFv}=$ cerebral blood flow velocity.
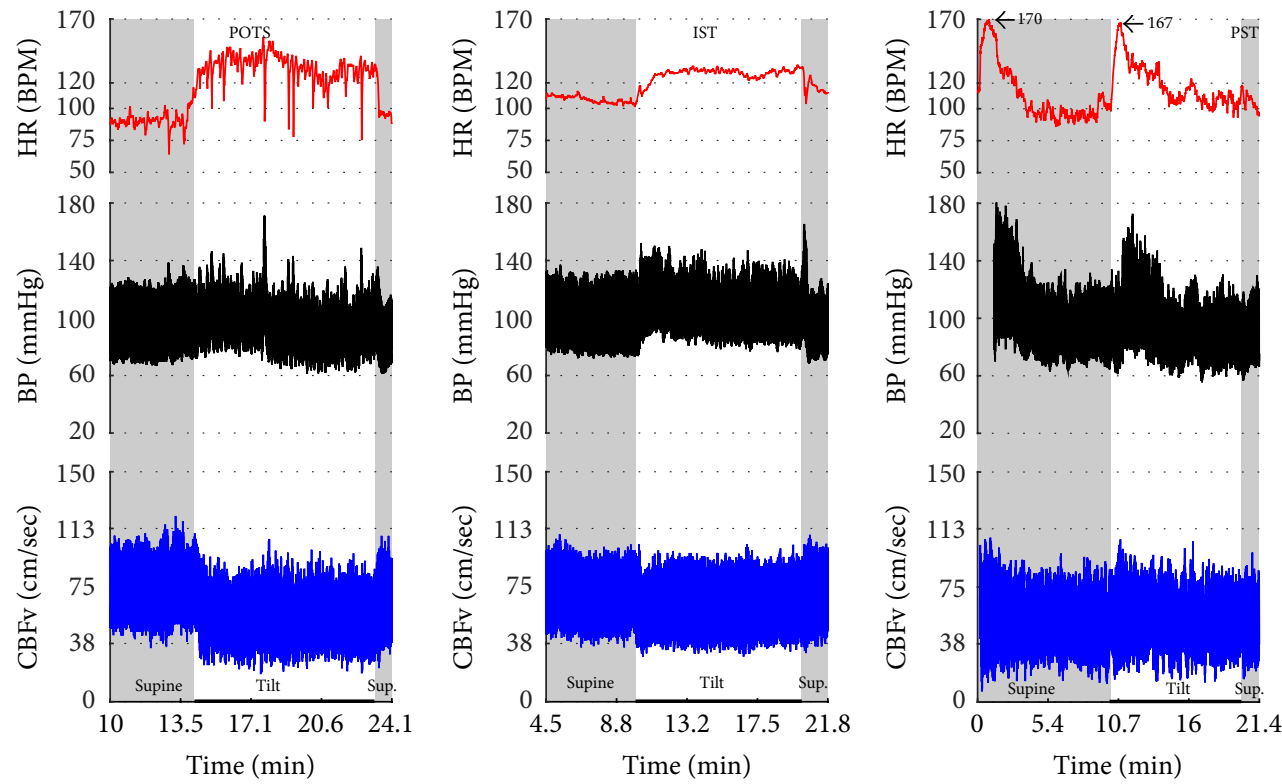

FIGURE 2: Comparisons of tachycardia syndromes including postural tachycardia syndrome (POTS), inappropriate sinus tachycardia (IST), and paroxysmal sinus tachycardia (PST). During supine position, the heart rate is normal $(<100)$ in POTS, consistently elevated in IST, and transiently elevated in PST. The excessive tachycardia during the tilt is seen in all shown syndromes, being continuous in POTS and IST, and intermittent in PST. Blood pressure is stable in all examples. CBFv is reduced in POTS, normal in IST, and intermittently elevated in PST.

and pCAF (1 patient). Characteristic patterns of syncope are seen in Figure 3 with details in Figures 8-11 and 17. All three types of syncope share common pattern in $\mathrm{CBFv}$ which is consistent with cerebral vasodilation (Figures 3 and 8-11).
Syncope can be superimposed on any pattern including IST (Figure 17).

$\mathrm{OH}$ can be progressive (Figures 1, 4, and 7), transient (Figure 5), associated with stable orthostatic CBFv, for example, 

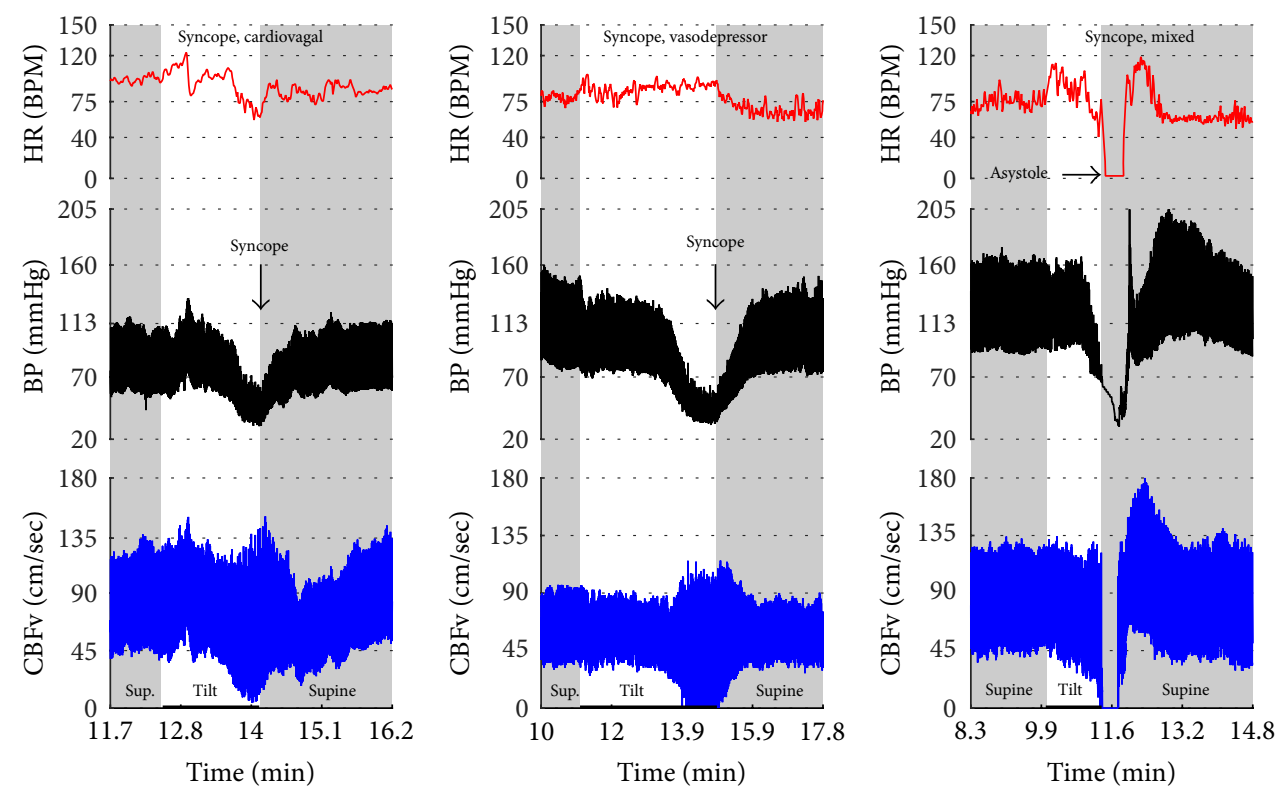

FIGURE 3: Comparisons of three main types of neurally mediated syncope. Syncope is associated with profound decline in BP and in diastolic CBFv. HR and BP responses differentiate each type of syncope while CBFv responses are similar among all syncope types. HR declines before BP in cardiovagal syncope. HR decline is absent in the vasodepressor syncope. HR and BP decline simultaneously in mixed syncope. CBFv shows typical vasodilation pattern in all types of syncope that is characterized by a decline in diastolic and increase in systolic CBFv. The diastolic $\mathrm{CBFv}$ is equal or close to zero during syncope.

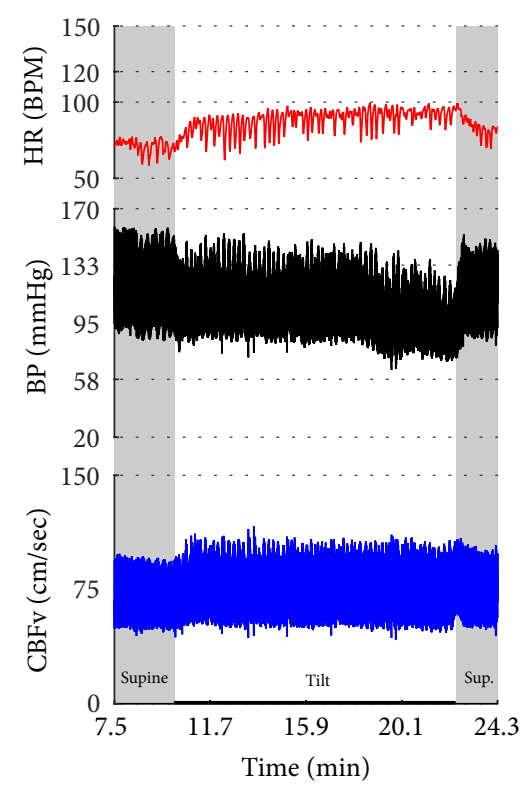

(a)

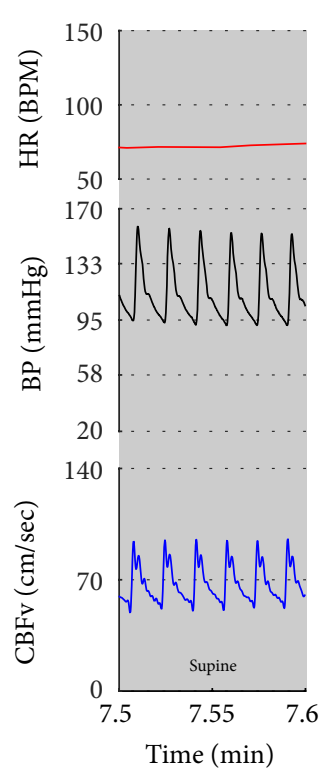

(b)

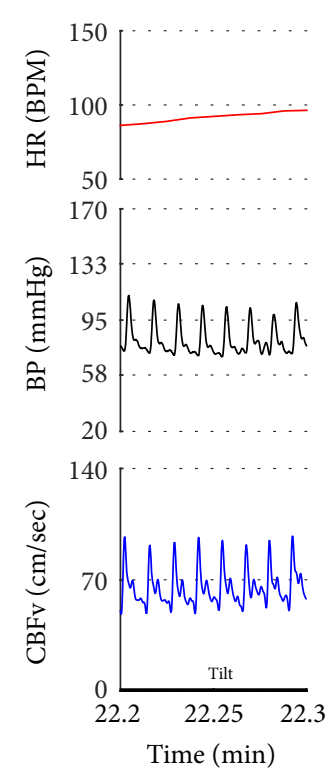

(c)

FIGURE 4: Orthostatic hypotension with stable orthostatic CBFv. There is immediate decline in BP at the onset of tilt and the decline further progressed towards the end of the tilt. The HR increment was normal and CBFv was stable during the tilt. Note details of signals in (b) and (c). Data from 60-year-old man.

compensated (Figures 4 and 5), or reduced orthostatic $\mathrm{CBFv}$, for example, uncompensated (Figures 6 and 7). Mean blood pressure was reduced in both $\mathrm{OH}$ groups while the $\mathrm{CBFV}$ tilt drop score was abnormal in the $\mathrm{OH}$-uncompensated group during the tilt (Table 2).
OCHOs (Figures 1, 12, and 20) showed primary reduction in orthostatic CBFv with normal orthostatic heart rate responses and without orthostatic hypotension.

In OHTN (Figure 13) orthostatic blood pressure was elevated while orthostatic CBFv was stable. 


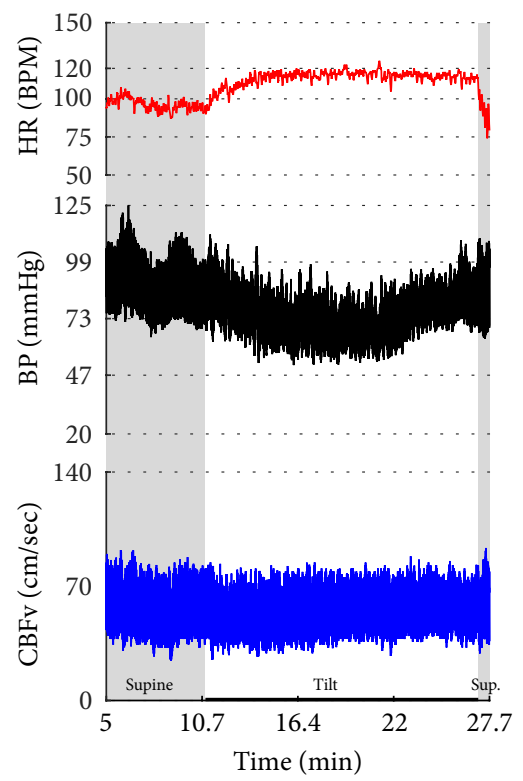

Figure 5: Transient orthostatic hypotension. This example shows a progressive decline in BP during the first 5 minutes of the tilt followed by the recovery of $\mathrm{BP}$ towards the end of the tilt. CBFv was normal and stable during the tilt. Data from 42-year-old woman.

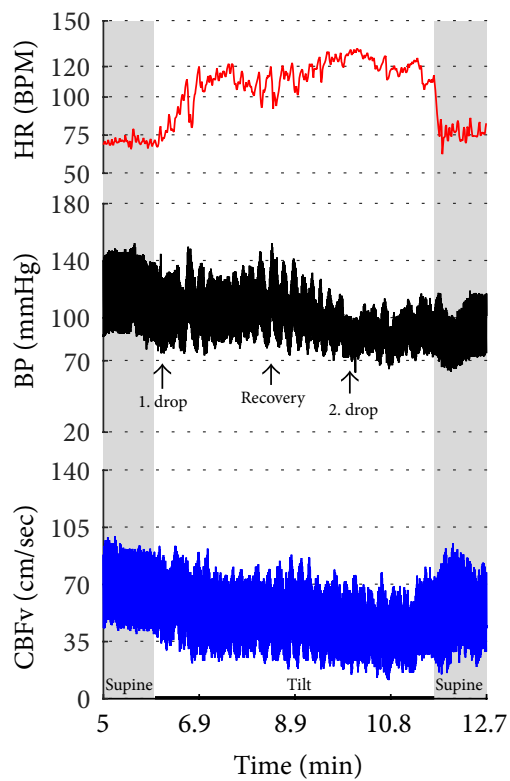

(a)

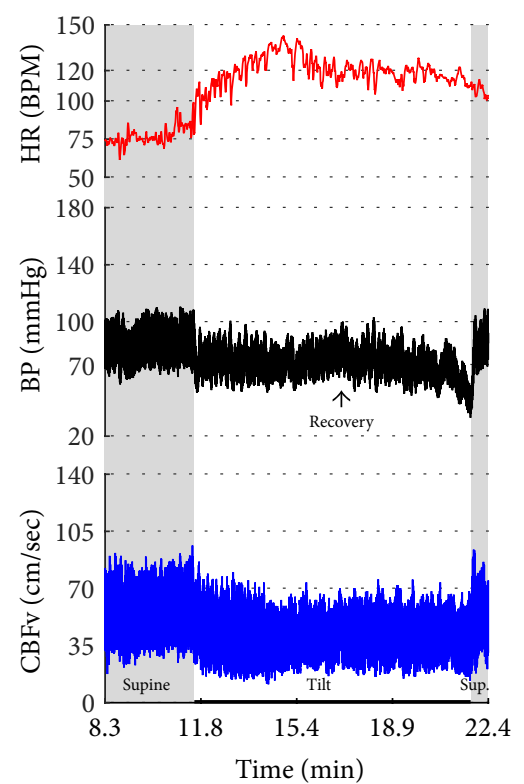

(b)

FIGURE 6: Orthostatic hypotension with reduced orthostatic CBFv. (a) shows the drop of BP (1. drop) at the beginning of the tilt with a recovery (recovery) followed by a further decline in $\mathrm{BP}$ at the second half of the tilt (2. drop). The HR increment was preserved during the tilt. $\mathrm{CBFv}$ was progressively declining during the tilt. Patient was very dizzy and anxious and she requested to terminate the tilt at the 6th minute. (b) shows data from the same person a year later. The second tilt test was remarkably similar to the first one showing orthostatic hypotension with similar recovery and final decline of the blood pressure. CBFv was reduced throughout the tilt. Data from 26-year-old woman.

Characteristic features of tachycardia syndromes (POTS, IST, and PST) are shown in Figures 2, 15-18, and 23 and Table 2. Both POTS and PST patients were younger than subjects with the normal tilt test and had elevated heart rate during the tilt. IST subjects were younger than subjects with the normal tilt response and had elevated heart rate in supine position and during the tilt.

Vasomotor oscillations (Figure 19), spurious fluctuations of blood pressure (Figure 20), and sustained drift in blood pressure (Figure 21) obtained from finger plethysmographic 


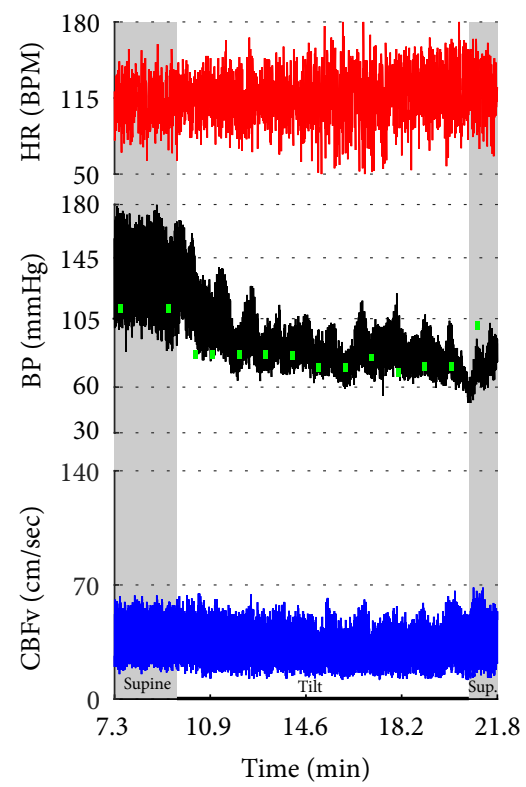

(a)

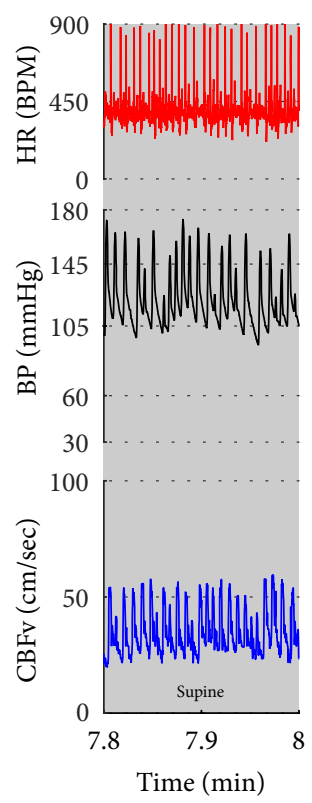

(b)

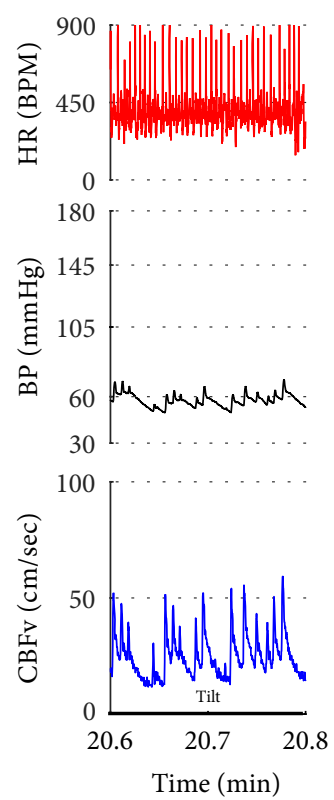

(c)

Figure 7: This example shows combination of (1) primary cerebral autoregulatory failure (pCAF); (2) severe orthostatic hypotension with reduced orthostatic CBFv; and (3) atrial fibrillation. Supine BP is elevated while supine CBFv is reduced. The pattern of elevated BP and reduced $\mathrm{CBFv}$ during supine position is due to abnormal cerebral vasoconstriction consistent with pCAF. There was severe $\mathrm{OH}$ with a progressive decrease in BP during the tilt. Diastolic CBFv was reduced during the tilt but less than systolic CBFv that can be seen in mild cerebral vasodilatation that compensates for reduced orthostatic BP. HR responses to the tilt were absent. Note random, noise-like pattern of HR due atrial fibrillation. The HR fluctuated wildly (50-180 BPM) and not all electrical systoles were transmitted in the mechanical systoles (c) resulting in marked variations of BP and CBFv. Supine hypertension and orthostatic hypotension are a marker of severe autonomic adrenergic failure. Green boxes represent mean blood pressure obtained from the arm. Data from 69-year-old man with multiple system atrophy.
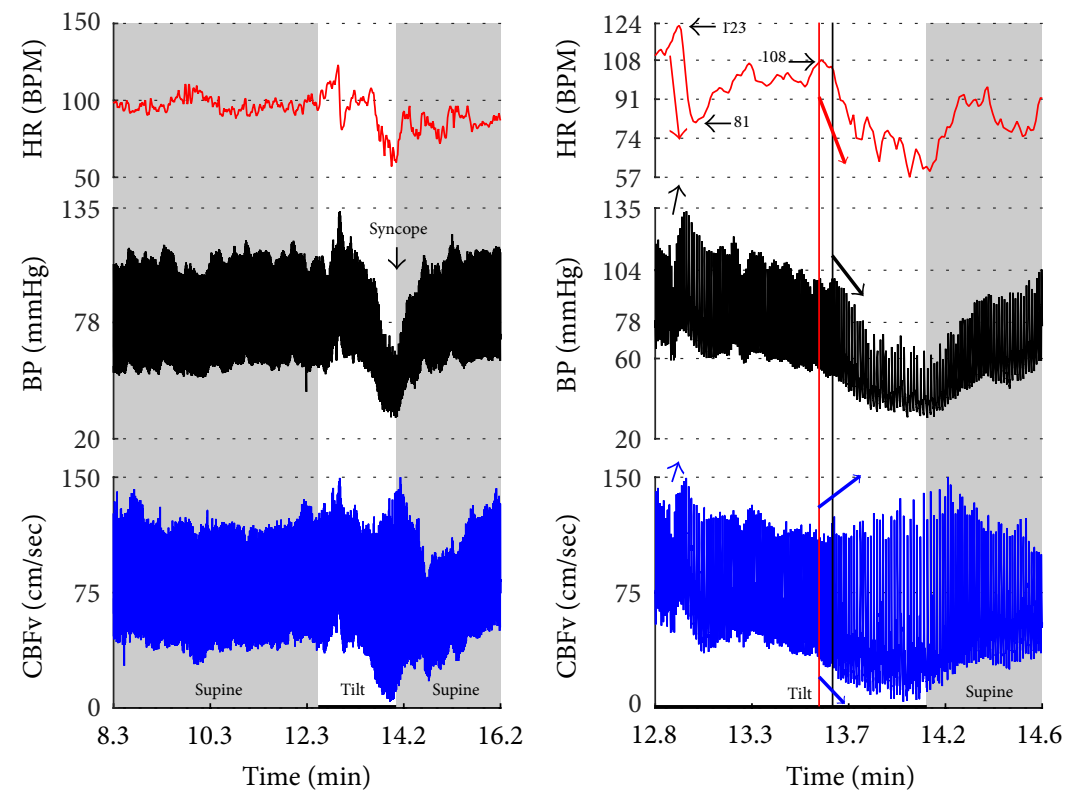

Figure 8: Mixed syncope. In this subject, initial slowing of HR from 123 to $81 \mathrm{BPM}$ (thin red arrow) is not cardioinhibitory response but reflects a functioning baroreflex since it is associated with elevation of BP (thin black arrow) and CBFv (thin blue arrow). The onset of the cardioinhibitory reaction is marked by the vertical red line with HR 108 BPM (thick red arrow) and coincides with a BP drop (thick black arrow) and patient became quickly unconscious. The pulsatility index increased during syncope (systolic CBFv increased and diastolic $\mathrm{CFBv}$ decreased) which is consistent with cerebral vasodilatation. The vasodilatation started early (thick blue arrows), and the changes were discernible in the doppler audio signal before noticeable changes in heart rate or BP. The cardiac slowing followed with delayed BP decrease being characteristic of cardioinhibitory syncope. Patient lost consciousness when the systolic BP declined below $60 \mathrm{mmHg}$, as expected. Data from 20 y/o woman. 

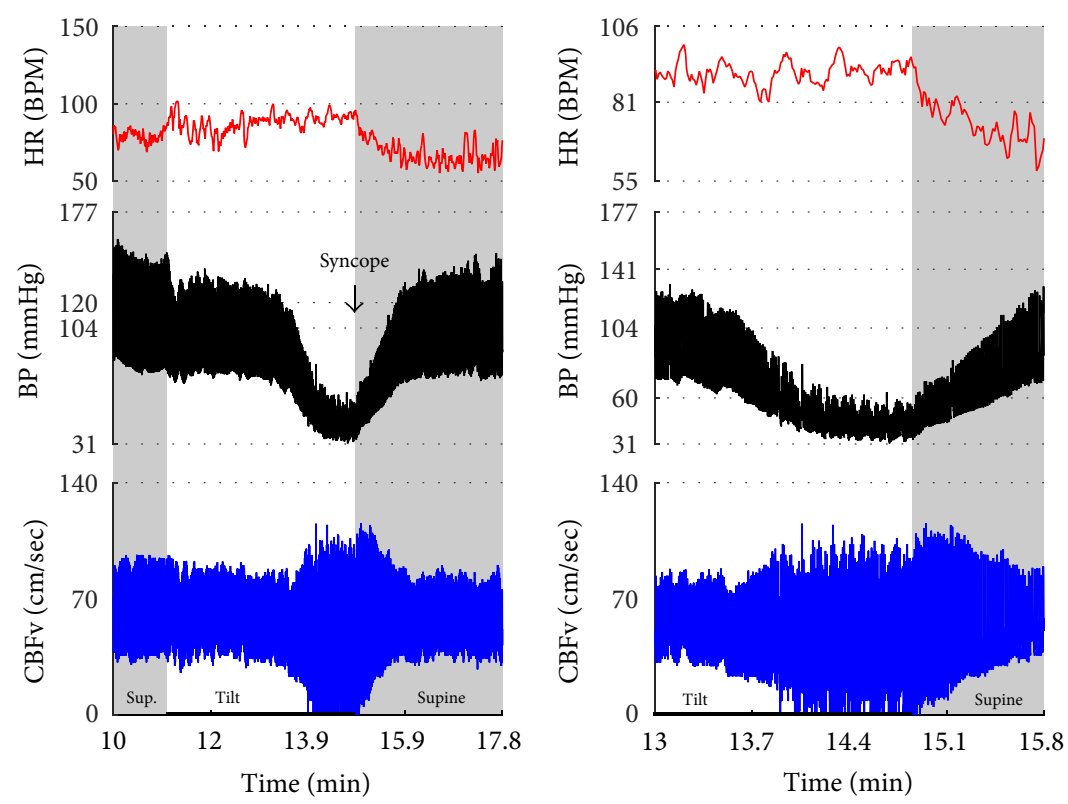

FIgURE 9: Vasodepressor syncope. There is a progressive drop in BP without bradycardia till syncope occurred. HR started to slow down only after a subject was tilted back to supine position. The syncope is associated with a characteristic cerebral vasodilatation pattern. Data from 27-year-old woman.

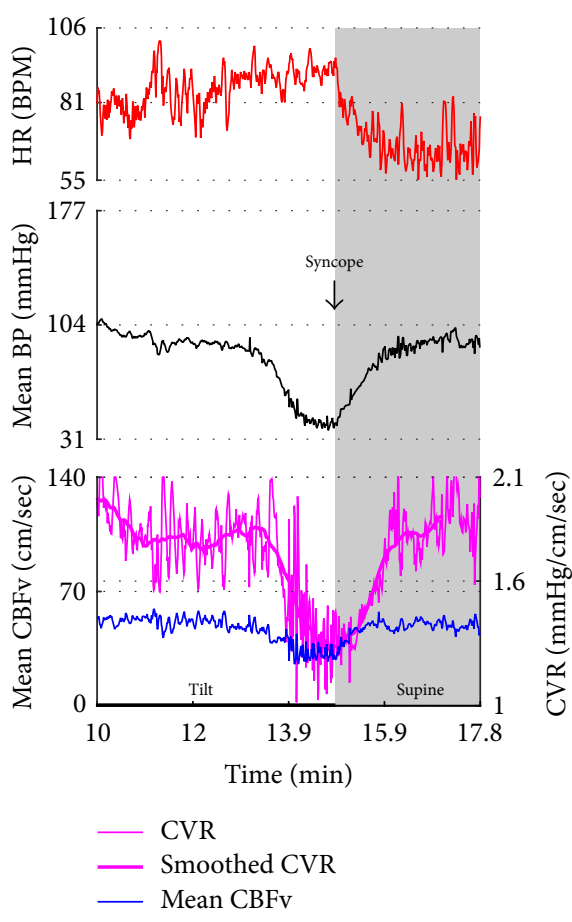

FIGURE 10: Cerebral vasodilation during syncope. The cerebral vascular resistance is reduced during syncope which is consistent with cerebral vasodilation. The same subject as in Figure 9.

device can be recognized by simultaneous recording of the arm blood pressure and CBFv.

Eight patients had pseudosyncope (Figures 22-23) with stable orthostatic CBFv. From these patients, tilt test showed normal responses in 4 subjects, POTS in 2 subjects, and $\mathrm{OH}$-compensated and mixed syncope in 1 subject. All these subjects regained consciousness during the tilt test by reassurance.

Patients with pCAF had reduced CBFv in the supine position, had elevated cerebral vascular resistance in supine position and during the tilt, and had abnormal drop of CBFv score during the tilt (Table 2).

Table 3 summarizes the main diagnostic features of common patterns encountered during the tilt test.

\section{Discussion}

This study showed head-to-head comparisons of common tilt test patterns. Characteristic pattern associated with a particular orthostatic syndrome can be grouped into abnormalities predominantly affecting heart rate (PST, IST, and POTS), blood pressure (syncope, $\mathrm{OH}$, and $\mathrm{OHTN}$ ), and cerebral blood flow (OCHOs, pCAF). Psychogenic pseudosyncope is associated with stable $\mathrm{CBFv}$ without any particular heart rate or blood pressure pattern. This study also showed that criteria for several orthostatic syndromes had to be modified to allow unambiguous pattern classifications.

4.1. Symptoms versus Tilt Diagnosis. Orthostatic symptoms, except of syncope, are nonspecific and in general poorly correlating with orthostatic blood pressure or heart rate. This study showed that orthostatic drop in CBFv is more sensitive and specific marker of prediction of orthostatic symptoms than orthostatic blood pressure changes. Therefore CBFv is better proxy for cerebral hypoperfusion than orthostatic hypotension. 

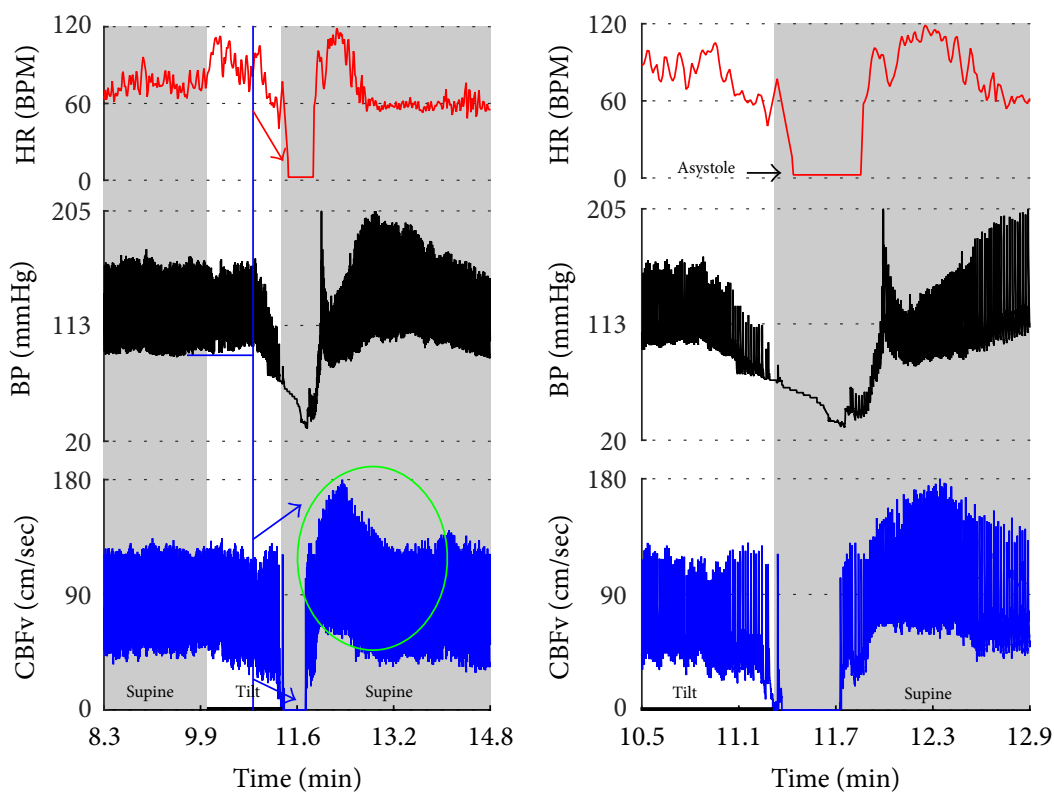

FIGURE 11: Cardioinhibitory syncope. In this subject, slowing of HR, BP drop, and cerebral vasodilation began almost simultaneously (marked by blue line) and progressed rapidly into asystole of 27 seconds. Note the vasodilatory pattern in CBFv early in the evolution of syncope (blue arrows) followed by reactive hyperemia (green circle) with elevated systolic and diastolic CBFv. Data from 39-year-old man.
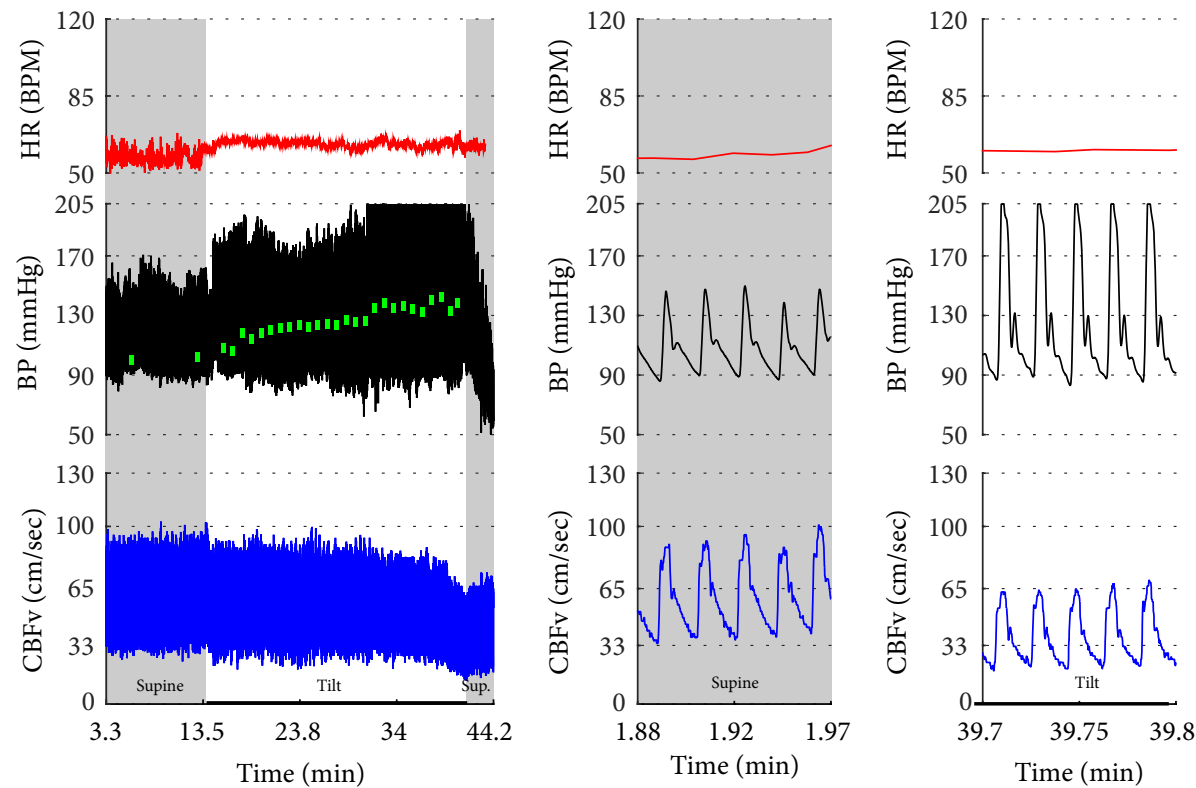

FIGURE 12: Orthostatic cerebral hypoperfusion syndrome (OCHOs). The tilt provoked a progressive increase in BP that was seen in both finger (black trace) and arm (green boxes) BP. The finger systolic BP exceeded the upper range of our device, $205 \mathrm{mmHg}$. The CBFv was progressively declining during the tilt that was consistent with cerebral vasoconstriction. Patient was very dizzy and agitated during the tilt. Data from 66-year-old woman.

Criteria for orthostatic syndromes are heterogeneous; some criteria are exclusively physiological (e.g., $\mathrm{OH}$ which can be symptomatic or asymptomatic) while the others require also the presence of symptoms, for example, POTS. Nevertheless, the information obtained from the tilt test should not be used in isolation but always on clinical ground.
4.2. Tachycardia Syndromes (PST, IST, and POTS). These syndromes share excessive heart rate increment. Primarily, it is the timing of tachycardia that distinguishes each syndrome. Using the nonmodified criteria, majority of patients with IST and PST satisfy also the POTS criteria. The ambiguities in determination of tachycardia syndromes were solved 

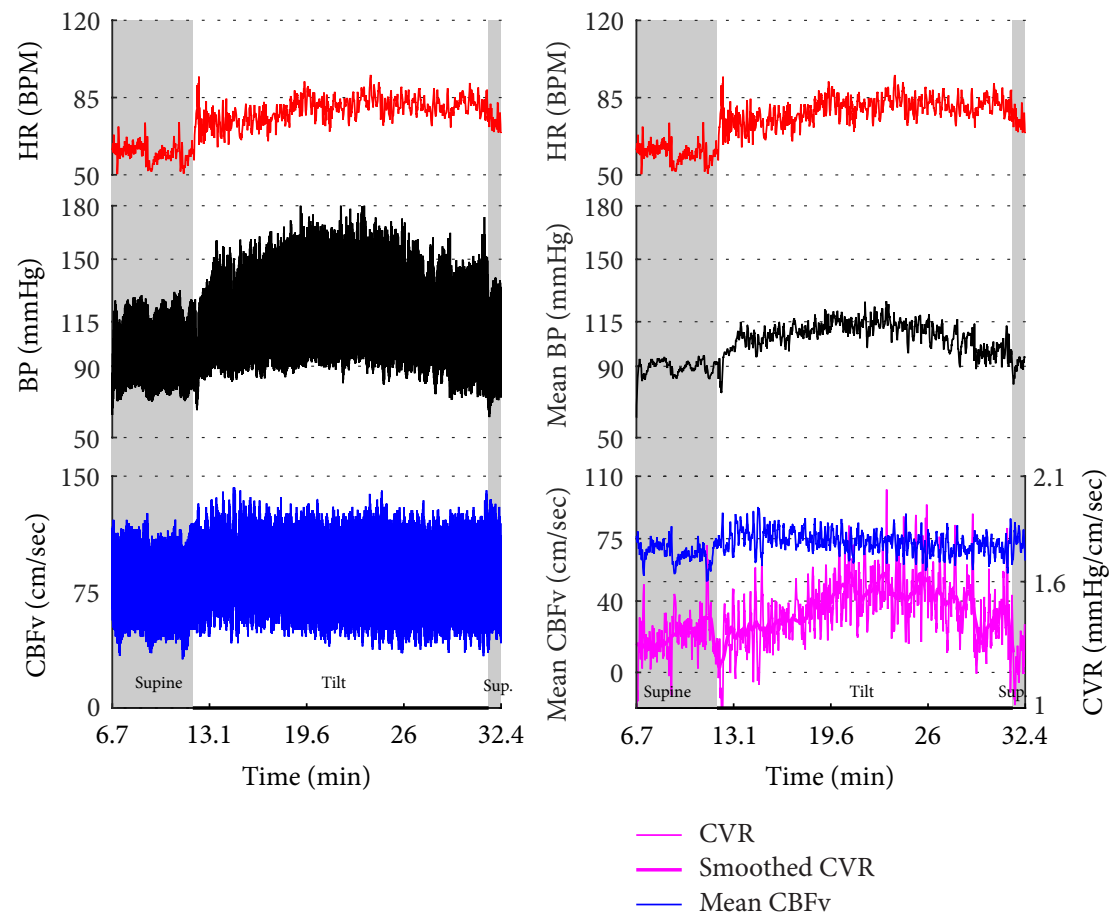

FIGURE 13: Orthostatic hypertension syndrome. BP was elevated during the tilt while CBFv was stable. HR responses were normal during the tilt. Note increased cerebral vascular resistance (CRV) that is consistent with cerebral vasoconstriction. Data from 39-year-old man.

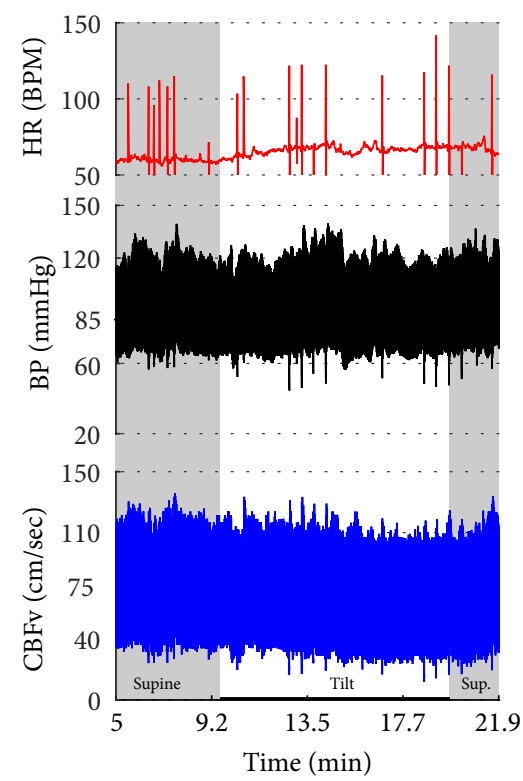

(a)

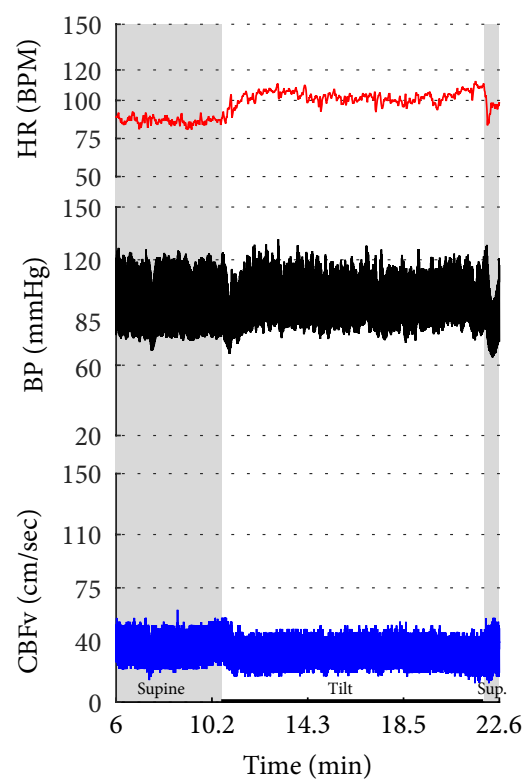

(b)

FIGURE 14: Primary cerebral autoregulatory failure (pCAF, (b)). HR and BP were normal at supine and during the tilt. CBFv was markedly reduced at the supine position and was further reduced during the tilt. Data from 47-year-old man. Patient was referred for evaluation of chronic fatigue, difficulites with attention, and chronic dizziness that was both supine and postural. For comparison, a healthy 80 -year-old woman has normal CBFv (a). 

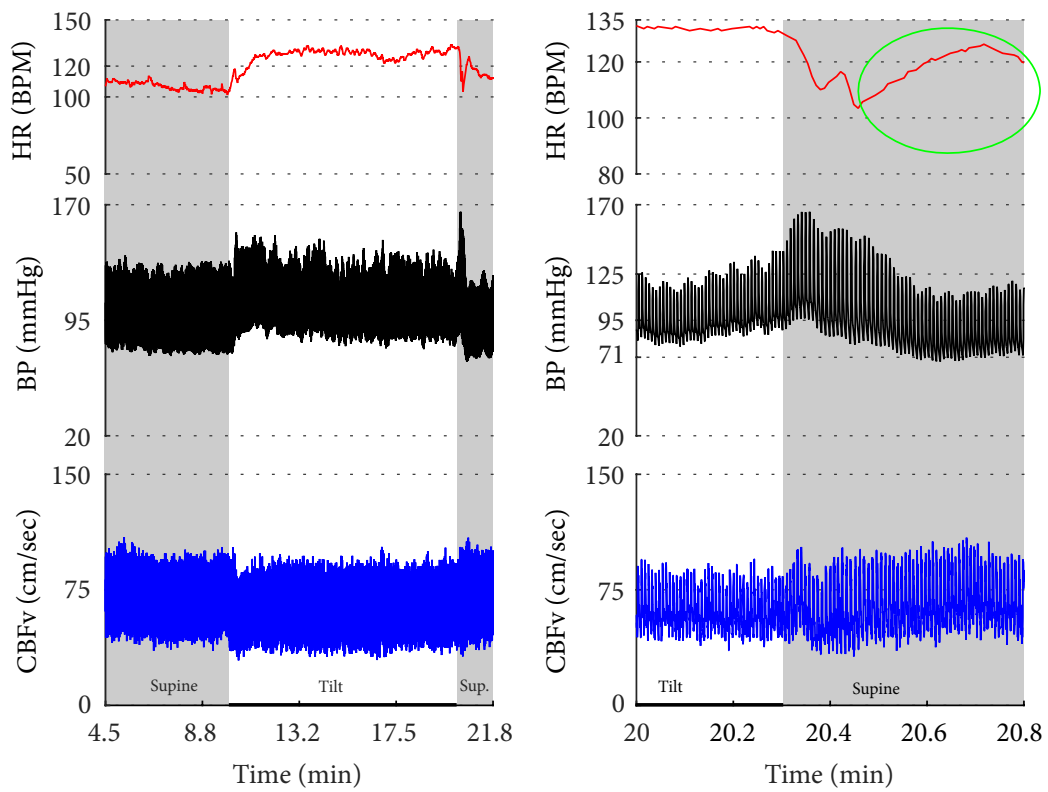

FIGURE 15: Inappropriate sinus tachycardia (IST). Note elevated resting heart rate ( $>100 \mathrm{BMP})$ which is further increased during the tilt. This response satisfies criteria for POTS (last baseline $\mathrm{HR}=101.3$, last HR during the tilt $=132.6$, and increment $>30 \mathrm{BPM}$ and $\mathrm{BPM}>120$ ) except that the continuous resting supine tachycardia is inconsistent with POTS. Second clue that this is not POTS is an episode of HR increment exceeding $120 \mathrm{BPM}$ (green oval) at supine position after completing the tilt. Mean supine HR $=106.6 \pm 2.8$, range 97.1-114.3 BPM, mean orthostatic HR $128 \pm 2.4$, and range 121.8-134.0 BPM.
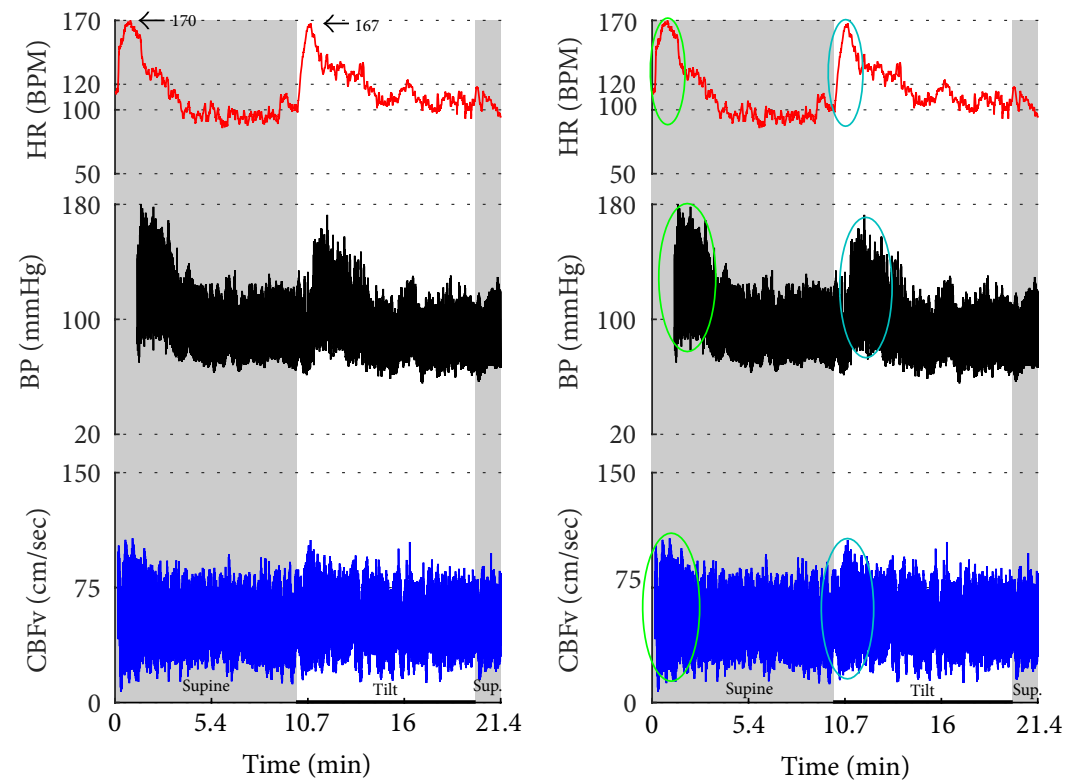

FIGURE 16: Paroxysmal sinus tachycardia (PST) due to anxiety. The patient, a 34 y/o woman, was referred for evaluation of postural tachycardia syndrome (POTS). During montage in supine position before placing the blood pressure sensor (i.e., why the initial portion of recording is missing), she became very anxious after she was informed that she will be tilted in several minutes. The anxiety was associated with transient tachycardia 170 BPM, elevated BP, and CBFv (green ovals). Similar pattern (transient tachycardia, elevated BP, and CBFv) was observed at the onset of the tilt (blue oval). The supine tachycardia of similar character to that of the tilt confirms that this is not POTS but IST. Furthermore, the tachycardia is usually sustained and/or it is progressively increased during the tilt in POTS. CBFv is usually unchanged or decreased in POTS during the tilt. 

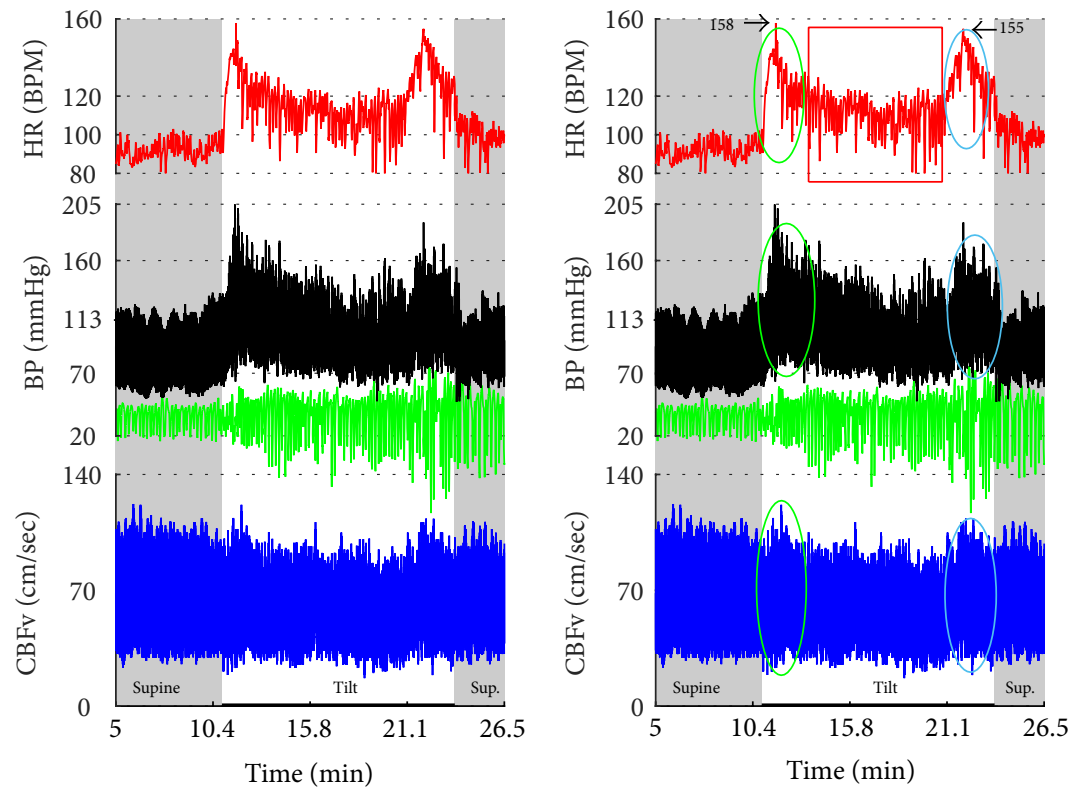

FIGURE 17: Postural tachycardia syndrome (POTS) or paroxysmal sinus tachycardia (PST) due to the anxiety reaction? The supine variables were normal. The tilt test induced initial tachycardia associated with elevation of BP and CBFv (green ovals). This reaction is due to anxiety since BP and CBFv are elevated. In POTS, CBFv is usually unchanged or reduced. Similar reaction occurred at the end of the tilt (blue ovals). Note that patient was hyperventilating during the tilt (green tracing). The tilt test was done without any medication. Trial of beta blockers failed to improve orthostatic intolerance. Final diagnosis was PST. Mean supine HR was $91.5 \pm 4.9$ BPM; mean orthostatic HR during more steady HR (demarcated by a red box) was $109.3 \pm 8.5$ BPM. The mean HR during the whole tilting was $118.5 \pm 13.8$ BPM. Data from 25 -year-old woman.
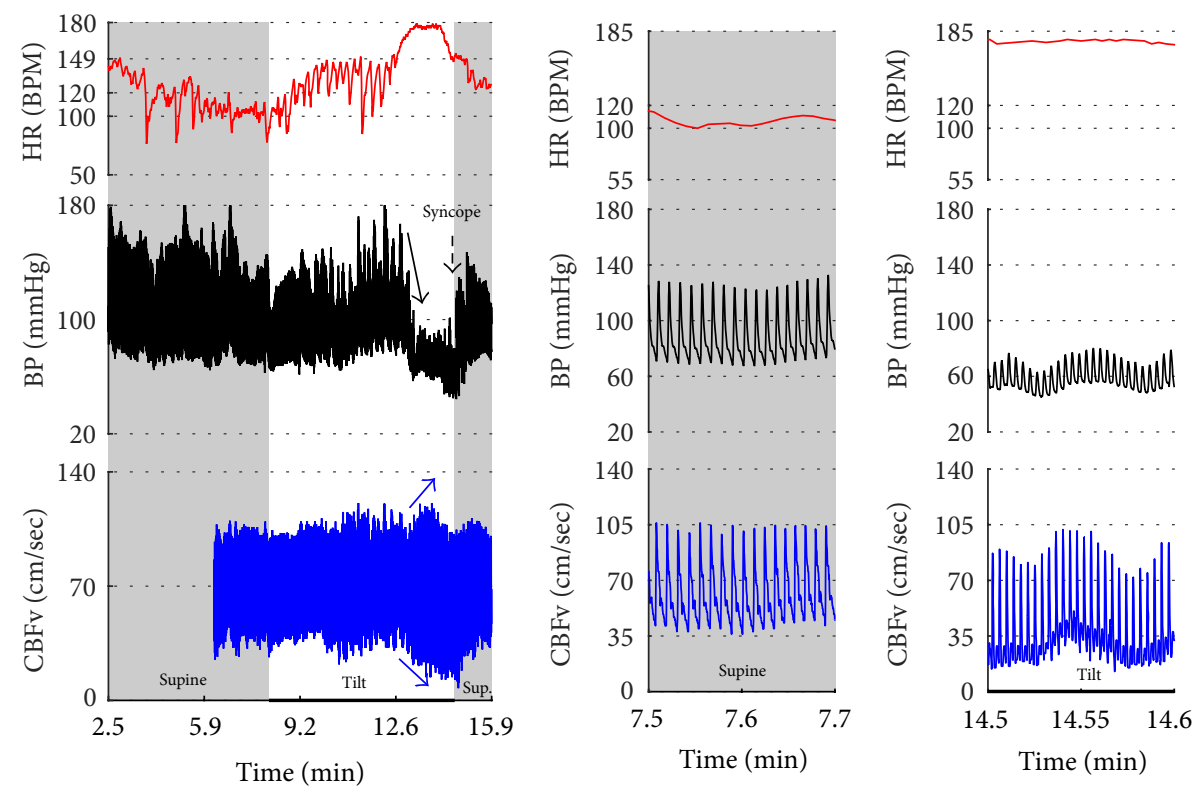

FIGURE 18: Inappropriate sinus tachycardia complicated by vasodepressor syncope. The average HR was above $100 \mathrm{BPM}$ with the maximal heart rate $149 \mathrm{BPM}$ during the supine position. The tilt provoked HR increase and marked oscillations in all signals including HR, BP, and CBFv. At the 5th minute of the tilt, BP suddenly declined (black arrow) that was accompanied by tachycardia $179 \mathrm{BPM}$ culminated in a syncope. The decline in $\mathrm{BP}$ without bradycardia is characteristic of vasodepressor syncope due to reduced peripheral resistance. $\mathrm{CBFv}$ declined and the pulsatility index (systolic CBFv - diastolic CBFv) increased (blue arrows) that indicates cerebral vasodilation. Data from 26-year-old woman. 

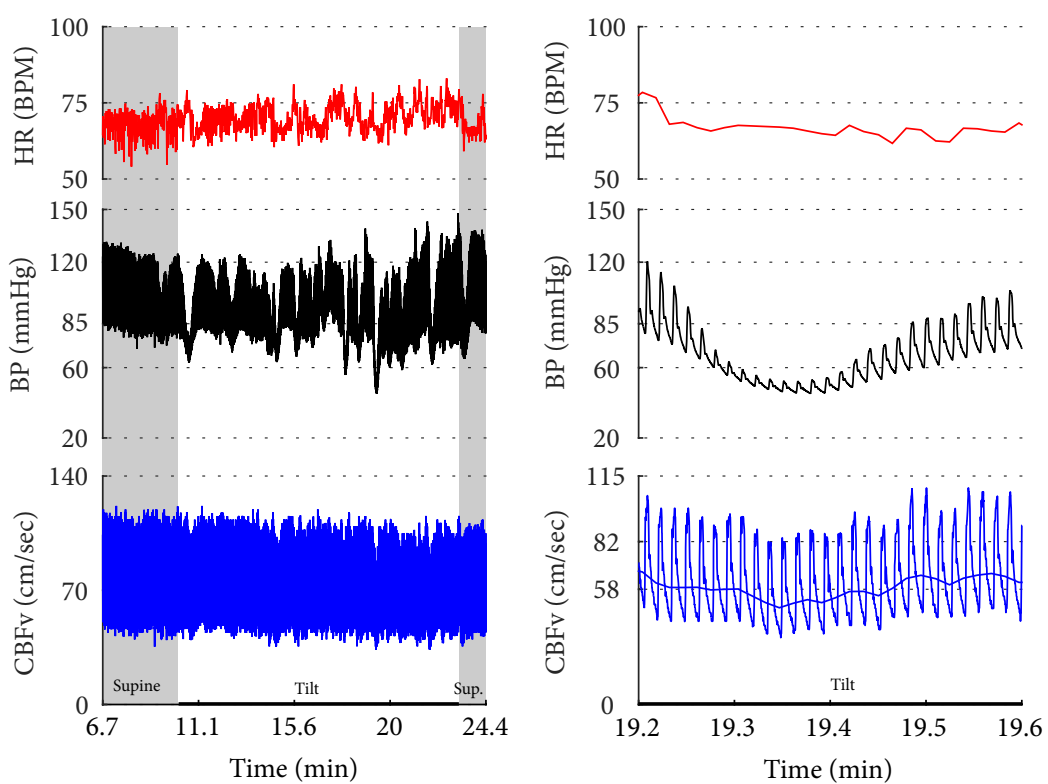

FIGURE 19: Vasomotor oscillations. Note marked fluctuations of BP occurring approximately every minute. CBFv also fluctuates in synchrony with BP. Patient was mildly anxious during the tilt test but she was not dizzy. Data from 47-year-old woman.

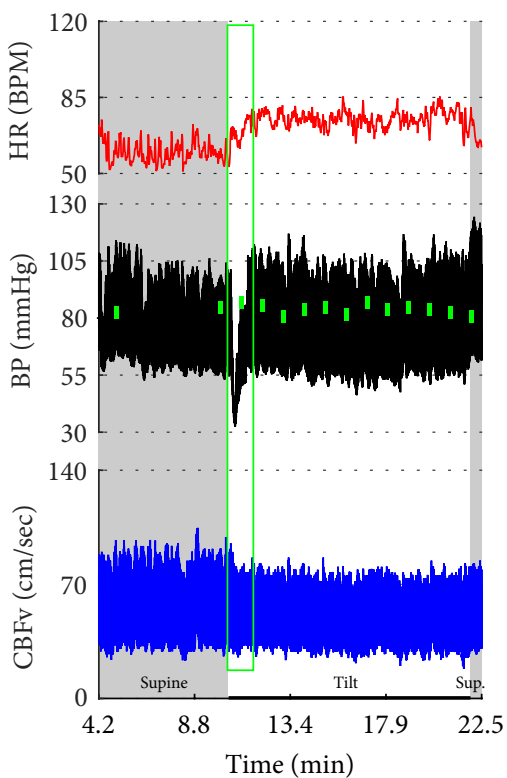

(a)

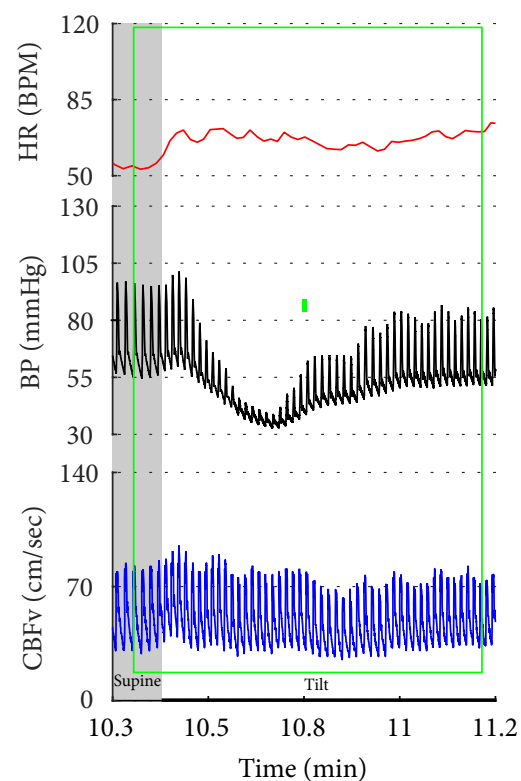

(b)

FIgURE 20: The transient drop in BP at the beginning of the tilt (designated by a green box) is artificial. The oscillometric device showed much higher BP (the small filled green box in (b)). Another clue that this is a technical artifact is the fact that there is no corresponding HR reaction and also CBFv is unchanged. The tilt test was normal. Data from 38-year-old woman.

by modifying the diagnostic criteria as mentioned in the Section 2. CBFv is also helpful in classification. CBFv is characteristically reduced in POTS, normal in IST, and normal or transiently elevated in PST.

4.3. Neurally Mediated Syncope. Neurally mediated syncope has a characteristic pattern. Loss of consciousness usually occurs if systolic blood pressure declines to $60 \mathrm{mmHg}$ [21] that is accompanied by cerebral vasodilation [15]. In this study, the CBFv pattern was similar in all types of syncope. The diastolic CBFv was close or equal to zero, the mean CBFv was less than $30 \mathrm{~cm} / \mathrm{sec}$, and pulsatility index increased which is consistent with cerebral vasodilation [15]. It is advantageous to use CBFv in differentiation of pseudosyncope or spurious decline in finger blood pressure; in both conditions $\mathrm{CBF}$ remains stable. 

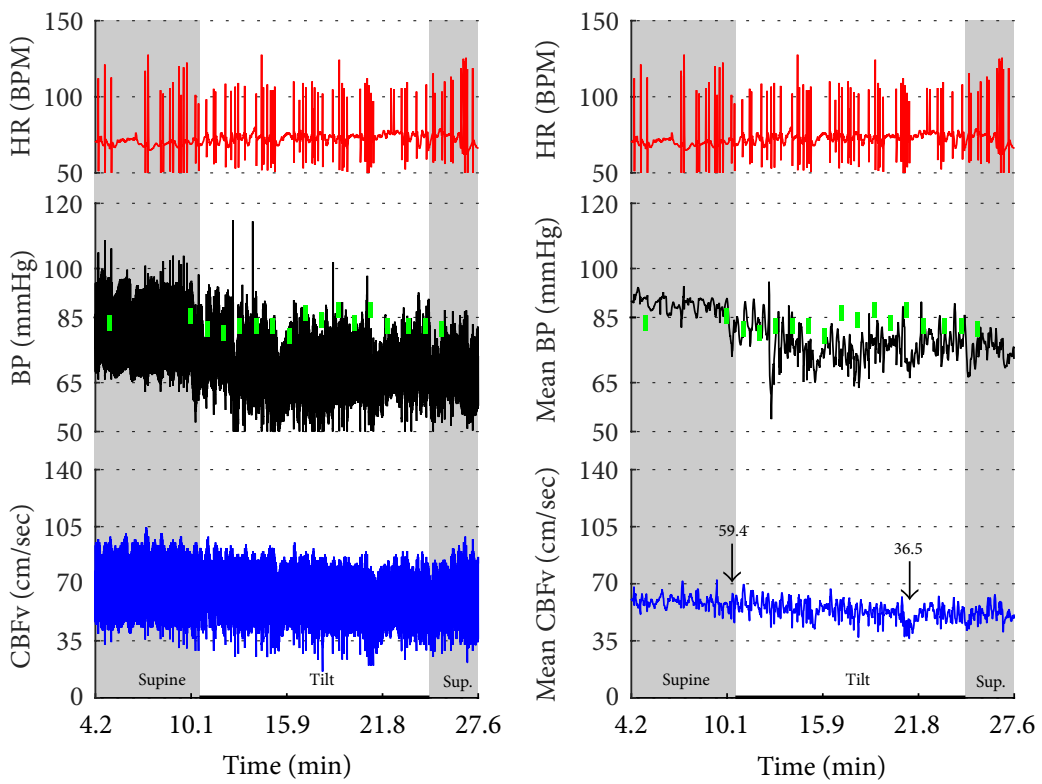

FIGURE 21: This example shows arteficial drift in the plethysmographic finger BP that may be misinterpreted as orthostatic hypotension. The spurious decline in BP continued in spite of multiple repositionings of a sensor. Note that oscillometric BP from the upper arm (green boxes) shows absent orthostatic hypotension. There are a number of extrasystoles in the HR. BP was interpreted as normal. CBFv responses to the tilt were abnormal as there was a drop in CBFv from the supine $59.4 \mathrm{~cm} / \mathrm{sec}$ to $36.5 \mathrm{~cm} / \mathrm{sec}$ at the end of the tilt. Patient was dizzy during the tilt. The final diagnosis was orthostatic cerebral hypoperfusion syndrome. Data from 43 -year-old man.

4.4. Primary Cerebral Autoregulatory Failure ( $P C A F)$. PCAF is defined as low supine $\mathrm{CBFv}$ without supine hypotension or other hemodynamic abnormalities that can explain low CBFv. Patients with pCAF have increased cerebral vascular resistance that may be due to cerebral autoregulatory failure [19]. $\mathrm{CBFv}$ is also reduced during the tilt in spite of stable orthostatic blood pressure, further pointing to altered cerebral autoregulation. It can be hypothesized that pCAF is associated with small vessel disease. This hypothesis is supported by a previous study that showed significant negative correlation between $\mathrm{CBFv}$ and severity of white matter abnormalities in the MRI which is a marker of small vessel disease [22]. Clinical significance of pCAF is unclear but $\mathrm{pCAF}$ may be a cause of cerebral dysfunction due to chronic cerebral hypoperfusion.

4.5. OHTN. Original definition of OHTN included only an increase of blood pressure during the tilt while heart rate and $\mathrm{CBFv}$ responses to tilting were not considered. These limitations can cause diagnostic overlap with POTS since occasional rise in blood pressure during tilting can be observed in the hyperadrenergic form of POTS [23]. Furthermore, the rise in blood pressure can be seen also in OCHOs. Consider an example in Figure 12, where the excessive rise in blood pressure is associated with drop in $\mathrm{CBFv}$ during the tilt test. This patient has diagnosis of OCHOs, but using the original OHTN criteria he also qualifies for diagnosis of OHTN. The above mentioned shortcomings were overcome by including the heart rate and $\mathrm{CBFv}$ responses in the OHTN definition (Table 1).

4.6. The Role of CBFv Monitoring during the Tilt Test. Typically, the tilt test uses heart rate and blood pressure responses in classification of results [24]. The usefulness of an additional $\mathrm{CBFv}$ monitoring during the tilt test can be demonstrated by comparing the yield of the tilt test with and without $\mathrm{CBFv}$ monitoring. Without $\mathrm{CBFv}$ and when using heart rate and blood pressure monitoring only, then all OCHOs subjects ( $13 \%$ or 97 subjects) will be labeled as having normal tilt test. Since they have orthostatic symptoms (100\% of OCHOs patients were symptomatic in this study) they may be misdiagnosed as having psychogenic, vestibular, or an unclassified disorder. Furthermore 67 (9\%) patients with diagnosis of pCAF would also be missed without using CBFv. CBFv also helps to differentiate PST, IST, and POTS and spurious blood pressure oscillations.

4.7. Pseudosyncope: Psychogenic Syncope. No specific changes in hemodynamic parameters except of stable CBFv have been found in this study. This is in contrast with a recent study [25] which observed elevated heart rate and blood pressure before and during the loss of consciousness. In this study no particular heart rate and blood pressure pattern could be detected. The difference in results may reflect different patient population evaluated in both studies. This study also found that pseudosyncope can be combined with other syndromes including syncope. $\mathrm{CBFv}$ monitoring appears to be invaluable 


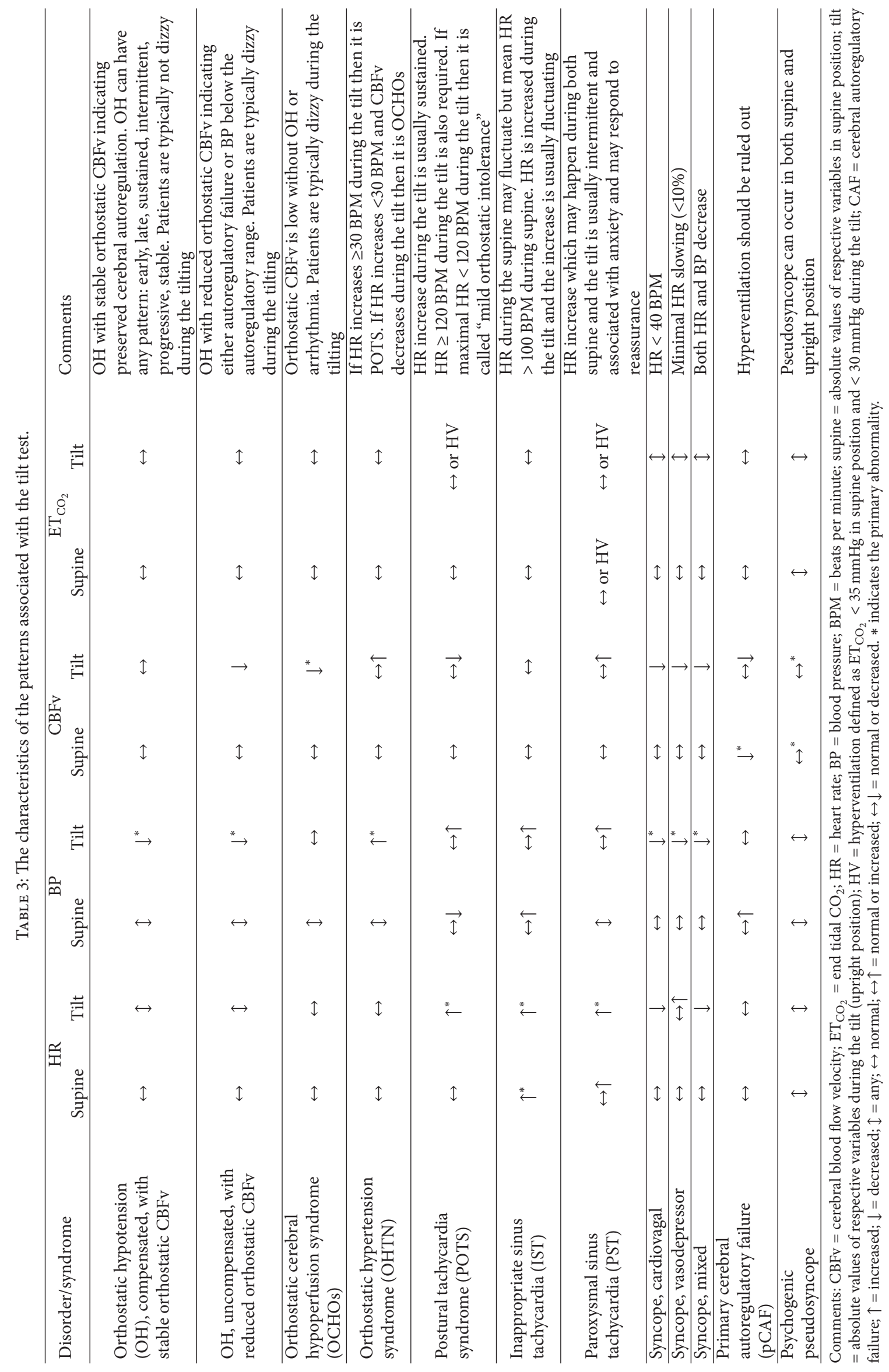




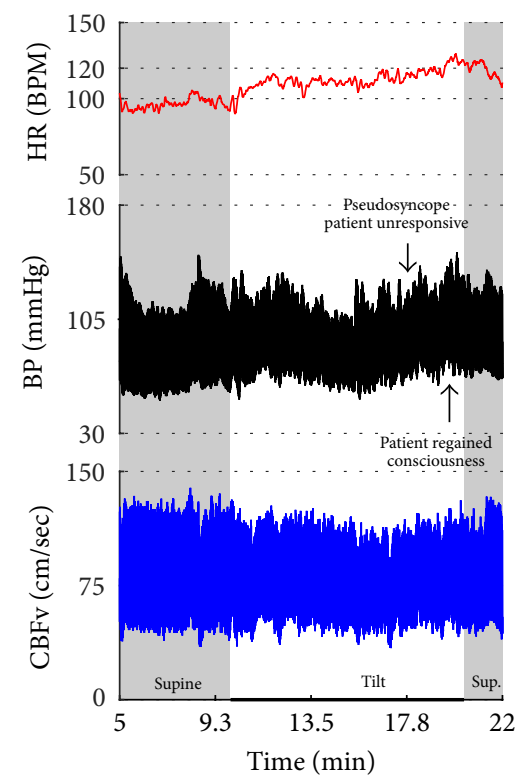

FIgURE 22: Psychogenic unresponsiveness. A patient became progressively obtunded and confused, experienced eyelid flutter, became aphasic, and finally did lose the consciousness during the tilt. The patient responded to reassurance and she regained consciousness while in the upright position. All monitoring variables were normal during the spell; patient became slightly tachycardiac after the spell. Data from 37-year-old woman.

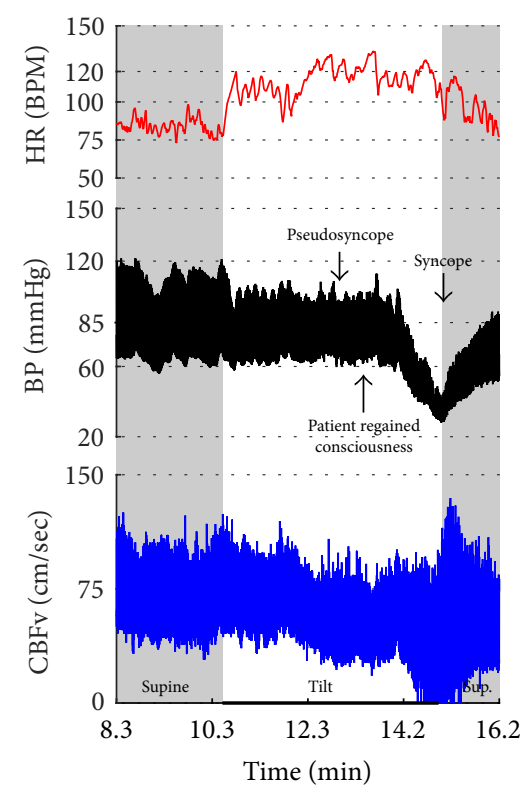

FIGURE 23: POTS + psychogenic unresponsiveness + syncope. The tilt provoked symptomatic excessive heart rate increment associated with a drop in CBFv without orthostatic hypotension which satisfies criteria for POTS. Then the patient became progressively less responsive which was consistent with pseudosyncope (psychogenic unresponsiveness) since $\mathrm{CBFv}$ was stable. The patient responded to reassurance and she regained consciousness later during the tilting. However, subsequently the patient experienced true mixed syncope at the 5th minute of the tilt (the tilt starts at minute 10.6 of the recording) and the tilt was terminated. Final diagnoses: (1) POTS; (2) psychogenic unresponsiveness; and (3) mixed syncope. Data from 21-year-old woman. in differentiation between pseudosyncope and syncope. The characteristic drop in $\mathrm{CBFv}$ associated with a vasodilatation pattern seen in syncope is missing in pseudosyncope.

4.8. Limitations of the Current Definitions of Orthostatic Syndromes. Ambiguities in definition of orthostatic syndromes were removed by adjusting the diagnostic criteria. Nevertheless, the clinical significance of adjusted criteria needs to be validated in future studies.

Table 3 summarizes common patterns associated with the tilt test and emphasizes the main features that enable differentiating each pattern.

\section{Conclusion}

Tilt test can be used as an add-on in diagnosis of orthostatic syndromes. However diagnostic criteria for several syndromes had to be made more explicit to allow unambiguous pattern classification. To be able to classify all patterns, it is essential to monitor $\mathrm{CBFv}$ in addition to blood pressure and heart rate.

\section{Competing Interests}

Peter Novak served on a scientific advisory board of Lundbeck. Study was funded by Department of Neurology, University of Massachusetts Medical School.

\section{Acknowledgments}

The author thanks Dr. Lan Qin, Shane Stanek, and Steve Smajkiewicz for their help in data collection.

\section{References}

[1] J. J. Smith, C. M. Porth, and M. Erickson, "Hemodynamic response to the upright posture," Journal of Clinical Pharmacology, vol. 34, no. 5, pp. 375-386, 1994.

[2] R. A. Kenny, A. Ingram, J. Bayliss, and R. Sutton, "Head-up tilt: a useful test for investigating unexplained syncope," The Lancet, vol. 1, no. 8494, pp. 1352-1355, 1986.

[3] A. Moya, R. Sutton, F. Ammirati et al., "Guidelines for the diagnosis and management of syncope (version 2009)," European Heart Journal, vol. 30, no. 21, pp. 2631-2671, 2009.

[4] V. Novak, J. M. Spies, P. Novak, B. R. McPhee, T. A. Rummans, and P. A. Low, "Hypocapnia and cerebral hypoperfusion in orthostatic intolerance," Stroke, vol. 29, no. 9, pp. 1876-1881, 1998.

[5] P. Novak, "Quantitative autonomic testing," Journal of Visualized Experiments, no. 53, Article ID e2502, 2011.

[6] P. Novak, "Quantitative scale for grading of cardiovascular autonomic reflex tests and small fibers from skin biopsies (QASAT)," Journal of Neurological Disorders, vol. 3, no. 2, article 226, 2015.

[7] R. S. Sheldon, B. P. Grubb, B. Olshansky et al., "2015 Heart rhythm society expert consensus statement on the diagnosis and treatment of postural tachycardia syndrome, inappropriate sinus tachycardia, and vasovagal syncope," Heart Rhythm, vol. 12, no. 6, pp. e41-e63, 2015. 
[8] P. A. Low, R. Schondorf, V. Novak, P. Sandroni, T. L. OpferGehrking, and P. Novak, "Postural tachycardia syndrome," in Clinical Autonomic Disorders, P. A. Low, Ed., pp. 681-697, Lippincott-Raven, 1997.

[9] W. B. Plash, A. Diedrich, I. Biaggioni et al., "Diagnosing postural tachycardia syndrome: comparison of tilt testing compared with standing haemodynamics," Clinical Science, vol. 124, no. 2, pp. 109-114, 2013.

[10] J.-S. Wu, Y.-C. Yang, F.-H. Lu, C.-H. Wu, and C.-J. Chang, "Population-based study on the prevalence and correlates of orthostatic hypotension/hypertension and orthostatic dizziness," Hypertension Research, vol. 31, no. 5, pp. 897-904, 2008.

[11] X.-H. Fan, K. Sun, X.-L. Zhou, H.-M. Zhang, H.-Y. Wu, and R.-T. Hui, "Association of orthostatic hypertension and hypotension with target organ damage in middle and old-aged hypertensive patients," Zhonghua Yi Xue Za Zhi, vol. 91, no. 4, pp. 220-224, 2011.

[12] J. Fessel and D. Robertson, "Orthostatic hypertension: when pressor reflexes overcompensate," Nature Clinical Practice Nephrology, vol. 2, no. 8, pp. 424-431, 2006.

[13] W. Wieling, D. L. Jardine, F. J. de Lange et al., "Cardiac output and vasodilation in the vasovagal response: an analysis of the classic papers," Heart Rhythm, vol. 13, no. 3, pp. 798-805, 2016.

[14] W. Wieling, D. L. Jardine, F. J. De Lange et al., "Cardiac output and vasodilation in the vasovagal response: an analysis of the classic papers," Heart Rhythm, vol. 13, no. 3, pp. 798-805, 2016.

[15] A. J. Ocon, Z. Messer, M. S. Medow, and J. M. Stewart, "Increased pulsatile cerebral blood flow, cerebral vasodilation, and postsyncopal headache in adolescents," The Journal of Pediatrics, vol. 159, no. 4, pp. 656-662.el, 2011.

[16] M. Brignole, C. Menozzi, A. Del Rosso et al., "New classification of haemodynamics of vasovagal syncope: beyond the VASIS classification. Analysis of the pre-syncopal phase of the tilt test without and with nitroglycerin challenge. Vasovagal Syncope International Study," Europace, vol. 2, no. 1, pp. 66-76, 2000.

[17] S. Yusuf and A. J. Camm, "The sinus tachycardias," Nature Clinical Practice Cardiovascular Medicine, vol. 2, no. 1, pp. 4452, 2005.

[18] B. Olshansky and R. M. Sullivan, "Inappropriate sinus tachycardia," Journal of the American College of Cardiology, vol. 61, no. 8, pp. 793-801, 2013.

[19] P. Novak, "Orthostatic cerebral hypoperfusion syndrome," Frontiers in Aging Neuroscience, vol. 8, article 22, 2016.

[20] V. Novak, P. Novak, and R. Schondorf, "Accuracy of beat-tobeat noninvasive measurement of finger arterial pressure using the Finapres: a spectral analysis approach," Journal of Clinical Monitoring, vol. 10, no. 2, pp. 118-126, 1994.

[21] R. Sheldon and S. Killam, "Methodology of isoproterenol-tilt table testing in patients with syncope," Journal of the American College of Cardiology, vol. 19, no. 4, pp. 773-779, 1992.

[22] V. Novak, D. Last, D. C. Alsop et al., "Cerebral blood flow velocity and periventricular white matter hyperintensities in type 2 diabetes," Diabetes Care, vol. 29, no. 7, pp. 1529-1534, 2006.

[23] P. A. Low, P. Sandroni, M. Joyner, and W.-K. Shen, "Postural tachycardia syndrome (POTS)," Journal of Cardiovascular Electrophysiology, vol. 20, no. 3, pp. 352-358, 2009.

[24] D. P. Saal, R. D. Thijs, and J. G. Van Dijk, "Tilt table testing in neurology and clinical neurophysiology," Clinical Neurophysiology, vol. 127, no. 2, pp. 1022-1030, 2016.
[25] M. R. Tannemaat, J. Van Niekerk, R. H. Reijntjes, R. D. Thijs, R. Sutton, and J. G. Van Dijk, "The semiology of tilt-induced psychogenic pseudosyncope," Neurology, vol. 81, no. 8, pp. 752758, 2013. 

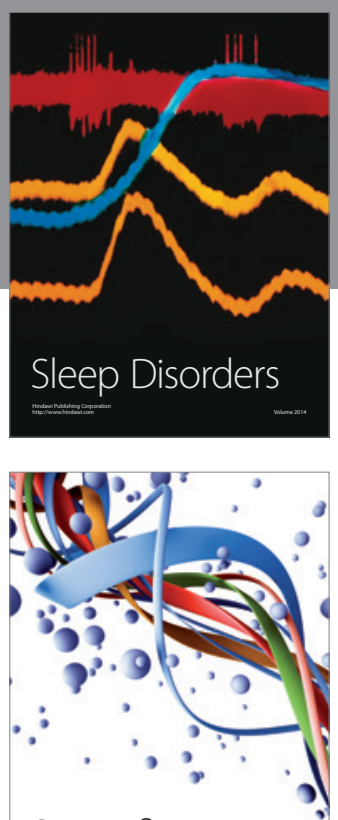

Scientifica
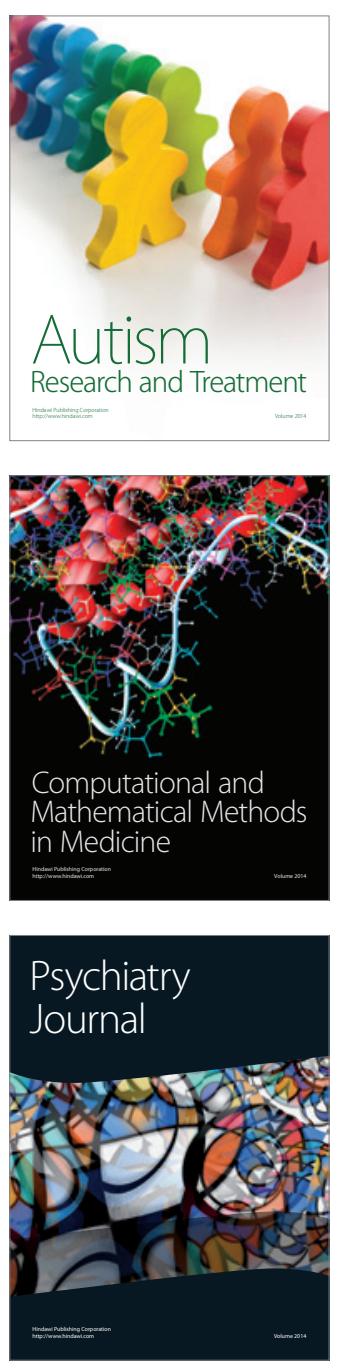
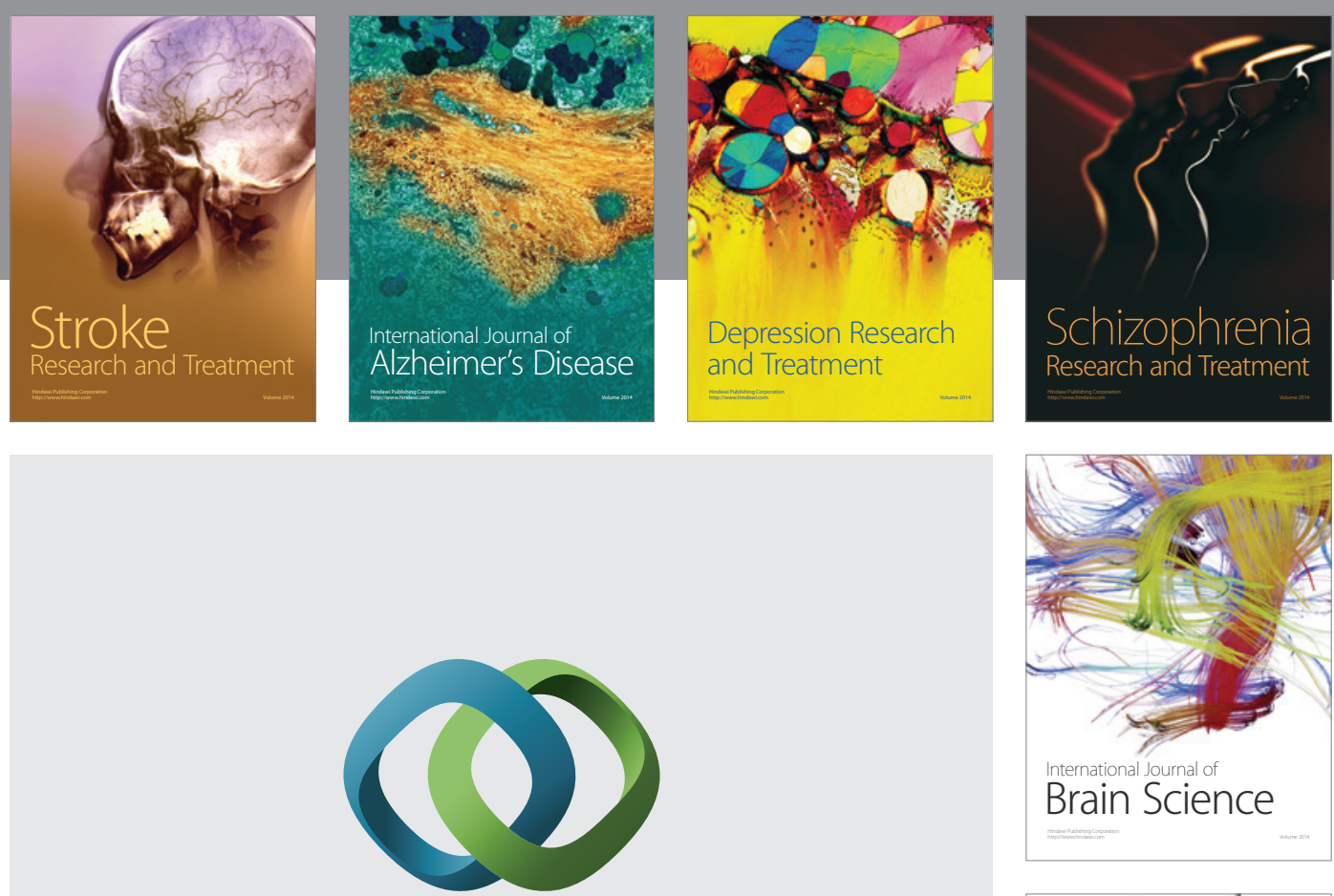

\section{Hindawi}

Submit your manuscripts at

http://www.hindawi.com
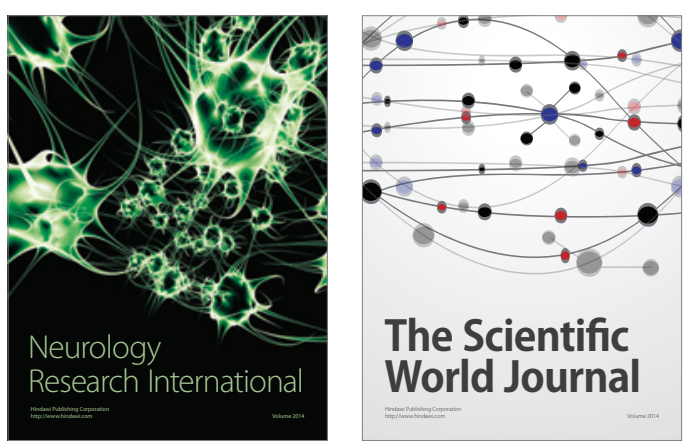

The Scientific World Journal

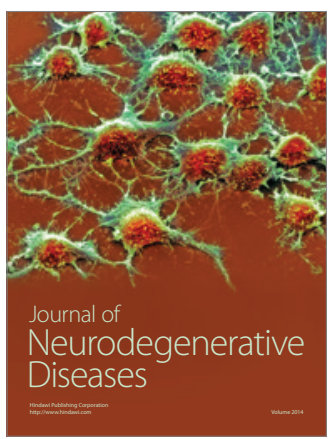

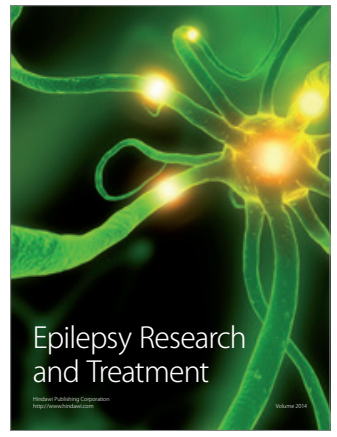

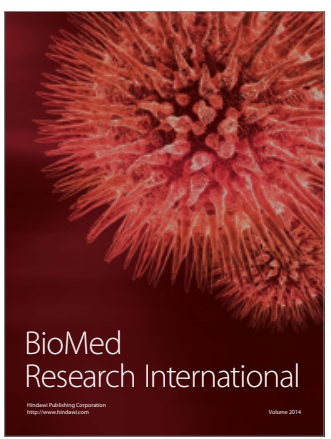

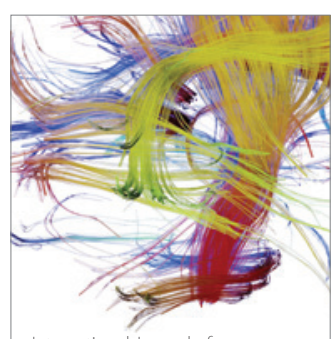

Brain Science

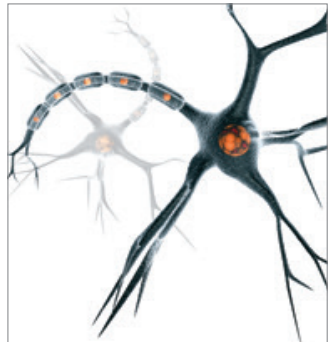

Neural Plasticity
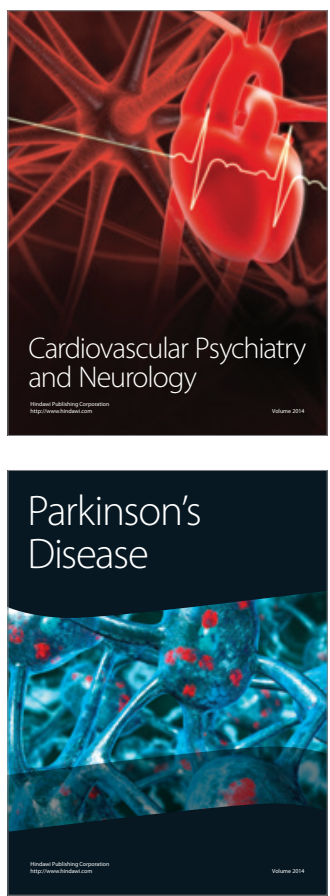